\title{
Feeding of High-Nickel Alloy Castings
}

\author{
KENT D. CARLSON, SHOUZHU OU, and CHRISTOPH BECKERMANN
}

Feeding of the nickel-based alloys CZ-100, M-35-1, and CW-12MW, as well as of the austenitic stainless steel $\mathrm{CN}-7 \mathrm{M}$, is investigated, using a combination of casting experiments and simulation. Casting trials are performed at five foundries, to produce a total of 55 plates of varying lengths and radiographic soundness levels. In order to develop the property databases necessary to simulate the casting of these alloys, temperature data are recorded for each alloy during the casting trials. These measured data are used in conjunction with material property simulation to develop the necessary property data for each alloy, including the solidification path. These property data are used to simulate the casting trials. Good agreement between the simulation results and the radiographic testing (RT) results for the castings is obtained. A quantitative relation between the measured ASTM X-ray levels and the predicted minimum Niyama criterion value is established for all but the CZ-100 alloy, which does not appear to suffer from shrinkage defects. A large number of additional simulations are used to develop general feeding distance (FD) rules. The new rules are shown to provide accurate FDs for the casting trial plates. The FDs of the high-nickel alloys (except CZ-100) are found to be at least 25 pct shorter than those for typical low-alloy steels.

\section{INTRODUCTION}

FEEDING distance (FD) in a casting is defined as the distance over which a riser can provide feed metal, resulting in a sound casting. This is an important concept for foundries, because the knowledge of FDs allows foundries to produce sound castings with a reasonable number of risers, which helps to maximize casting yield. Due to the importance of FDs, a great deal of effort has been expended to develop rules to determine riser FDs in steel castings. In 1973, the Steel Founders' Society of America (SFSA) published a foundry handbook entitled Risering Steel Castings ${ }^{[1]}$ this handbook provided charts, nomographs, and equations for calculating FDs for carbon and low-alloy (C\&LA) and several high-alloy steels. While the feeding guidelines in this handbook have been widely used in industry for the past 30 years, it is generally accepted that these rules can be overly conservative in many situations.

To address the need for more accurate, less conservative feeding rules, the authors of the present study developed a new set of C\&LA FD rules, ${ }^{[2,3,4]}$ followed by an analogous set of rules for high-alloy steel grades $\mathrm{CF}-8 \mathrm{M}, \mathrm{CA}-15, \mathrm{HH}, \mathrm{HK}$, and HP. ${ }^{[5]}$ Both sets of rules were developed by performing both plate-casting trials and corresponding casting simulations of these trials. Through this work, a correlation was developed between the Niyama criterion (a local thermal parameter) and radiographic soundness. It was found that the same correlation was valid for both C\&LA and high-alloy steels. Once this correlation was established, a large number of simulations were performed in order to determine FDs for a wide variety of casting conditions. Based on the resulting information, a new set of FD rules was developed. These rules are designed to produce radiographically sound castings at 2 pct sensitivity. Rules are provided for both end-effect and lateral FDs for top

KENT D. CARLSON, Assistant Research Engineer, SHOUZHU OU, Postdoctoral Research Associate, and CHRISTOPH BECKERMANN, Professor, are with the Department of Mechanical and Industrial Engineering, The University of Iowa, Iowa City, IA 52242. Contact e-mail: becker@ engineering.uiowa.edu

Manuscript submitted May 17, 2005. risers, as well as the FD for side risers. In addition, multipliers are provided to apply these rules with end chills and drag chills, as well as to tailor these rules to different alloy compositions (both C\&LA and high-alloy steels), sand mold materials, and pouring superheats. These new rules are shown to provide longer FDs in most casting situations than do the previously published rules.

The objective of the present study is to develop new FD rules for four additional alloys: three nickel-based alloys (CW12MW, CZ-100, and Monel-35-1) and an austenitic stainless steel $(\mathrm{CN}-7 \mathrm{M})$ with a large nickel content. In the study, they are collectively referred to as high-nickel alloys. The nominal compositions for each of these alloys are provided in Table I. No published feeding rules are presently available for these alloys. The rules for the high-nickel alloys are developed in a manner similar to the C\&LA and high-alloy rules discussed earlier. Plate-casting trials are performed in conjunction with corresponding casting simulations, to provide correlations between simulation variables and experimental results. Once the correlations are developed, extensive additional simulation is used to develop FD rules for a wide range of casting conditions. Unfortunately, the solidification path and thermophysical properties (thermal conductivity, density, etc.) needed to simulate the casting of the high-nickel alloys of interest here are not well established. These data were determined in the present work by coupling temperature measurements taken during the casting trials with property data computed from the software package JMatPro. ${ }^{[6]}$ The JMatPro package calculates the solidification path and all casting-relevant material properties for a given alloy composition, using thermodynamic databases for certain classes of alloys. The temperature measurements are primarily used to adjust and verify the computed solidification path from JMatPro, and also to validate the actual casting simulations.

This article is organized as follows. Section II describes the casting trials and provides the radiographic testing (RT) results. Section III details the property development for these alloys. Section IV describes the casting simulations and presents a comparison of the simulation results with the radiographic inspection data. The development of the FD rules 


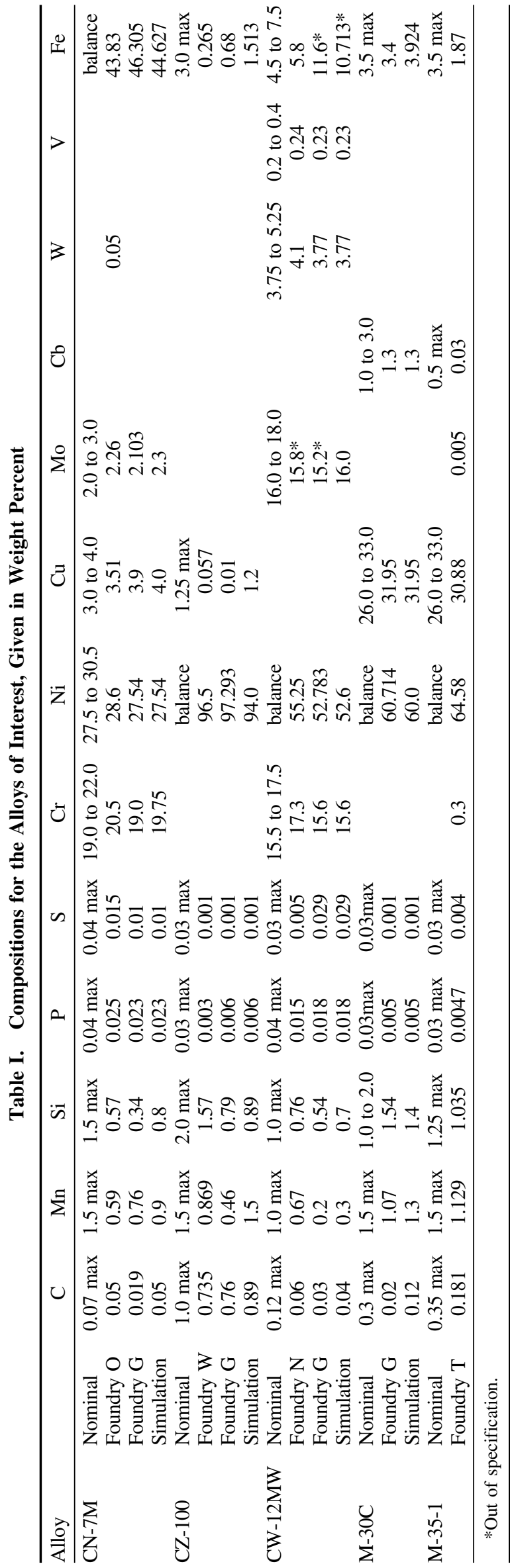

is presented in Section V. The conclusions of the present study are summarized in Section VI.

\section{CASTING TRIALS}

Five foundries participated in the nickel-alloy FD trials. All the foundries cast multiple lengths of plates $T=1 \mathrm{in}$. $(2.54 \mathrm{~cm})$ thick by $W=8 \mathrm{in} .(20.32 \mathrm{~cm})$ wide. This choice of plate thickness and width is typical of the section sizes for which FD rules are to be developed. ${ }^{[2-5]}$ The lengths, $L$, were chosen to produce plates ranging from radiographically sound to very unsound. A schematic of the general casting configuration is provided in Figure 1. A single top riser on one end of the plate is used to feed the shrinkage. In terms of gating, this schematic is approximate; each foundry used a typical gating system for this type of casting. Trial data such as alloy composition, sand mold composition, pouring temperature, and pouring time were collected during the trials, for later use in simulations. The alloy compositions each foundry measured during the casting trials are listed below each alloy's nominal composition in Table I. Note that the alloy M-30C appears in this table. This is because Foundry G cast M-30C rather than M-35-1; while these alloys are similar (compare the nominal compositions in Table I), their resulting properties are different enough to warrant distinguishing between the alloys. Another note regarding Table $\mathrm{I}$ is that the $\mathrm{CW}-12 \mathrm{MW}$ compositions cast by both Foundries $\mathrm{N}$ and $\mathrm{G}$ are out of specification. Foundry $\mathrm{N}$ used a molybdenum content that is slightly below specification, and Foundry $\mathrm{G}$ has both molybdenum and iron contents that are out of specification.

As mentioned in Section I, it was necessary to collect temperature data during the casting of the alloys investigated in this work, in order to develop the property databases that would be used to simulate the casting trials and validate the casting simulations themselves. All temperature measurements were performed at Foundry G, during the casting trials of the alloys CN-7M, CZ-100, CW-12MW, and M-30C carried out there. During the trials, B-type thermocouples (TCs) (Pt-6 pct $\mathrm{Rh}-\mathrm{Pt}-30$ pct $\mathrm{Rh}$ ) were used. The wires were encased in alumina ceramic tubes, which were inserted into fused quartz tubes for protection from thermal shock. A schematic of the rigging used for the TC plate trials is shown in Figure 2. Two

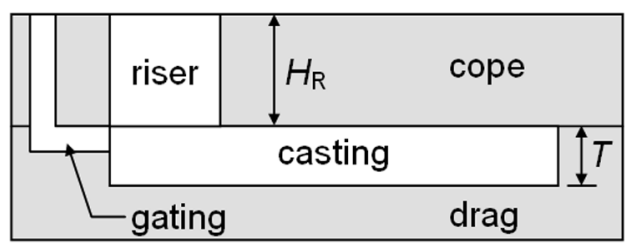

side-view

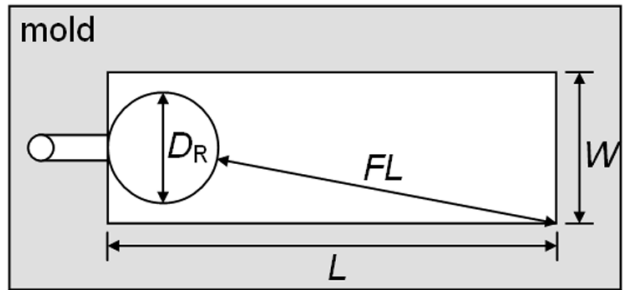

top-view

Fig. 1-General configuration for the high-nickel-alloy plate-casting trials. 

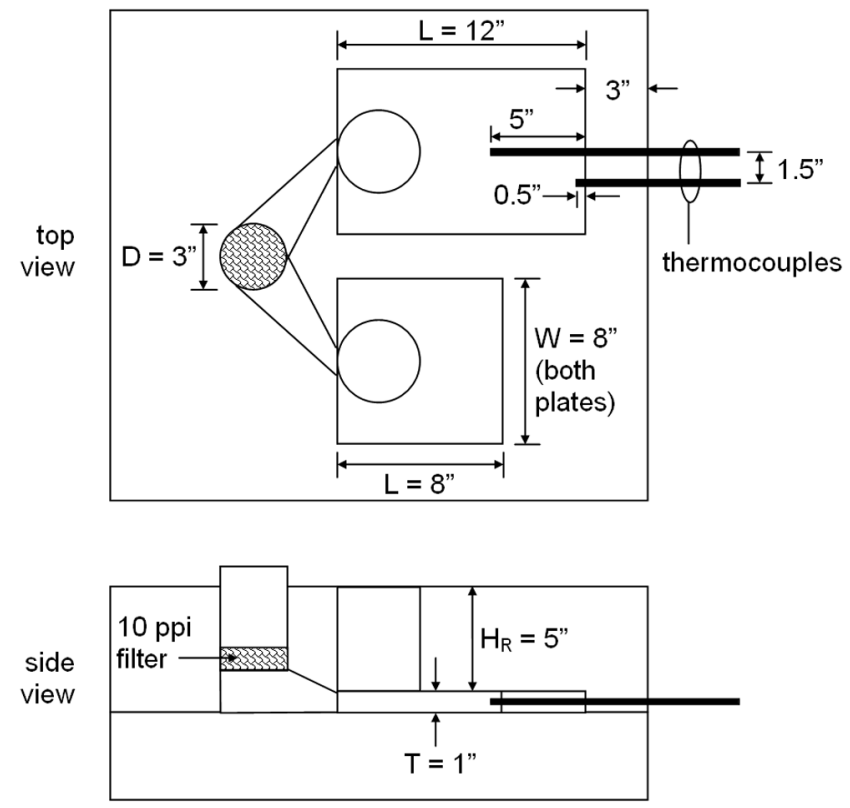

Fig. 2-Schematic of the rigging used for the TC trials.

plates, one 8 in. $(20.32 \mathrm{~cm})$ and one 12 in. $(30.48 \mathrm{~cm})$ long, were cast in each mold. For each alloy, one plate, 12 in. (30.48 cm) long, was rigged with two TCs: (1) a mid-plate TC that extends $5 \mathrm{in}$. $(12.7 \mathrm{~cm})$ from the end opposite to the riser into the plate, and (2) an end-plate TC that extends 0.5 in. $(1.27 \mathrm{~cm})$ into the plate. The two TCs were connected to a Personal Daq ${ }^{[7]}$ portable data-acquisition system. Six of the eight TCs were completely successful in recording temperature data, while two TCs failed during solidification. The temperature data collected during the trials are presented in Section III.

After the plates were cast, the foundries had each plate examined using RT according to ASTM E94 ${ }^{[8]}$ procedures, using $\mathrm{E} 446^{[9]}$ reference radiographs (for casting sections up to $2 \mathrm{in}$. $(5.08 \mathrm{~cm})$ thick). Based on this examination, an ASTM shrinkage RT level was assigned to each plate. Table II lists the details for each plate cast by foundry, including alloy, plate length, riser size, sand mold type, and the resulting shrinkage X-ray level for the plate. Note that an X-ray level of 0 is assigned to some plates, even though this level does not exist in ASTM E94. This was done in an attempt to designate those plates that are completely sound radiographically, since level 1 allows for some indications. Also note that some plates have two shrinkage levels listed, with one in parentheses. In these cases, the first value is the shrinkage rating for the plate away from the riser, and the value in parentheses is a rating for the underriser shrinkage. Because under-riser shrinkage is related to riser size and not to FD, the under-riser ratings were not used to develop the FD correlations.

The experimental shrinkage RT results from the casting trials are presented in Figures 3 through 6 for each of the four high-nickel alloys. In each of these figures, the feeding length (FL) for each plate cast is plotted against its resulting ASTM shrinkage X-ray level. The FL, shown schematically in Figures 3 through 6, is defined as the distance from the riser to the furthest point in the casting section being fed by that riser. The FL is purely geometrical, and implies nothing about casting soundness; it should not be confused with the FD defined in the Introduction, which is the longest distance over which a riser can provide feed metal to produce a radiographically sound casting. In Figures 3 through 6, the hollow symbols represent the individual plates, with different symbols representing the different foundries. The numbers next to the hollow symbols indicate how many plates that symbol represents. The solid squares represent the average X-ray level for all plates with a given FL. The bold numbers next to these solid squares indicate their numerical value. The error bars associated with these squares indicate one standard deviation around the mean. Note that the mean and standard deviation values shown on these figures are not intended to provide valid statistical information; the number of plates at each FL is too small to provide any meaningful statistical data. These are merely included to provide some indication about how the average X-ray levels change with FL, and to show the amount of scatter at a given FL. Figures 3 through 6 show that, as expected, the X-ray level generally increases with FL. The shortest plates are sound (level 0 or 1 ), while the longest plates are usually very unsound (levels 3 through 5). An important exception is the results for the CZ-100 alloy (Figure 4): all measured X-ray levels are either 0 or 1 , indicating that the FD of these $1 \mathrm{in} .(2.54 \mathrm{~cm})$ thick plates exceeds $12.6 \mathrm{in} .(30.0 \mathrm{~cm})$, which corresponds to the longest plates cast. It is believed that the formation of graphite during the solidification of this relatively high-carbon (1 wt pct, maximum) alloy causes some volumetric expansion that balances the metal shrinkage and prevents the formation of centerline shrinkage cavities. Finally, note that the variations in X-ray levels at a given FL are well within the uncertainty of interpreting the radiographic films. ${ }^{[10]}$

\section{SOLIDIFICATION PATH AND THERMOPHYSICAL PROPERTIES}

The temperature data recorded for each alloy were used in conjunction with simulation to determine the solidification path and material properties of each alloy before, during, and after solidification. For each alloy, the measured composition was entered into the software package JMatPro, ${ }^{[6]}$ which determines the solidification path and all casting-relevant material properties through thermodynamic calculations. Once these properties were calculated, they were entered into the casting simulation software MAGMASOFT, ${ }^{[11]}$ and the TC casting trials were simulated using exactly the conditions recorded during the trials (e.g., pouring superheat, mold composition, and gating). The TCs were included as a user-defined material in the MAGMASOFT simulations, and temperature and cooling rate $v s$ time curves were calculated for various locations in the vicinity of the TC beads. These predicted temperature and cooling rate curves were compared with the measured curves, and adjustments to several aspects of the simulations were made to bring these curves into agreement, as described later. Plots showing the measured temperature and cooling rate curves together with the final simulated curves for each alloy are shown in Figures 7 through 10; these figures will be used to explain the adjustments that were made. The scale on the left of Figures 7 through 10 is for the temperature curves; the scale on the right is for the cooling rate curves.

Before comparing the measured and predicted temperatures, it is necessary to determine from the measured data 
Table II. Experimental Data from the High-Nickel-Alloy Plate-Casting Trials

\begin{tabular}{|c|c|c|c|c|c|c|c|c|c|c|}
\hline Alloy & $\begin{array}{c}\mathrm{T} \times \mathrm{W} \\
\text { (in.) }\end{array}$ & $\begin{array}{l}\text { Length } \\
\text { (in.) }\end{array}$ & $\begin{array}{c}\text { Feeding } \\
\text { Length (in.) }\end{array}$ & $\begin{array}{c}\text { Riser } \\
\mathrm{D} \times \mathrm{H} \text { (in.) }\end{array}$ & $\begin{array}{c}\text { Pouring } \\
\text { Temp. }\left({ }^{\circ} \mathrm{C}\right)\end{array}$ & $\begin{array}{l}\text { Pouring } \\
\text { Time (s) }\end{array}$ & $\begin{array}{c}\text { Hot } \\
\text { Topping }\end{array}$ & $\begin{array}{c}\text { Shrinkage } \\
\text { X-ray Level }\end{array}$ & $\begin{array}{l}\text { Sand } \\
\text { Mold }\end{array}$ & Foundry \\
\hline$\overline{\mathrm{CN}-7 \mathrm{M}}$ & $1 \times 8$ & 8 & 5.3 & $4 \times 5$ & 1608 & 10 & no & 1 & furan sand & $\mathrm{G}$ \\
\hline $\mathrm{CN}-7 \mathrm{M}$ & $1 \times 8$ & 8 & 5.3 & $4 \times 5$ & 1558 & 10 & no & 1 & furan sand & G \\
\hline $\mathrm{CN}-7 \mathrm{M}$ & $1 \times 8$ & 8 & 5.3 & $4 \times 4$ & 1496 & 7 & no & 0 & furan sand & $\mathrm{O}$ \\
\hline $\mathrm{CN}-7 \mathrm{M}$ & $1 \times 8$ & 8 & 5.3 & $4 \times 4$ & 1492 & 7 & no & 0 & furan sand & $\mathrm{O}$ \\
\hline CN-7M & $1 \times 8$ & 8 & 5.3 & $4 \times 4$ & 1487 & 7 & no & 0 & furan sand & $\mathrm{O}$ \\
\hline $\mathrm{CN}-7 \mathrm{M}$ & $1 \times 8$ & 8 & 5.3 & $4 \times 4$ & 1496 & 7 & yes & 0 & furan sand & $\mathrm{O}$ \\
\hline CN-7M & $1 \times 8$ & 10 & 6.9 & $4 \times 5$ & 1589 & 10 & no & 2 & furan sand & $\mathrm{G}$ \\
\hline $\mathrm{CN}-7 \mathrm{M}$ & $1 \times 8$ & 10 & 6.9 & $4 \times 5$ & 1589 & 10 & no & 2 & furan sand & $\mathrm{G}$ \\
\hline $\mathrm{CN}-7 \mathrm{M}$ & $1 \times 8$ & 10 & 6.9 & $4 \times 5$ & 1561 & 10 & no & 2 & furan sand & $\mathrm{G}$ \\
\hline $\mathrm{CN}-7 \mathrm{M}$ & $1 \times 8$ & 10 & 6.9 & $4 \times 5$ & 1561 & 10 & no & 2 & furan sand & $\mathrm{G}$ \\
\hline CN-7M & $1 \times 8$ & 12 & 8.8 & $4 \times 5$ & 1608 & 10 & no & 3 & furan sand & $\mathrm{G}$ \\
\hline $\mathrm{CN}-7 \mathrm{M}$ & $1 \times 8$ & 12 & 8.8 & $4 \times 5$ & 1558 & 10 & no & 5 & furan sand & $\mathrm{G}$ \\
\hline $\mathrm{CN}-7 \mathrm{M}$ & $1 \times 8$ & 16 & 12.6 & $4 \times 4$ & 1496 & 10 & no & 4 & furan sand & $\mathrm{O}$ \\
\hline CN-7M & $1 \times 8$ & 16 & 12.6 & $4 \times 4$ & 1492 & 10 & no & 3 & furan sand & $\mathrm{O}$ \\
\hline $\mathrm{CN}-7 \mathrm{M}$ & $1 \times 8$ & 16 & 12.6 & $4 \times 4$ & 1487 & 10 & no & 2 & furan sand & $\mathrm{O}$ \\
\hline CN-7M & $1 \times 8$ & 16 & 12.6 & $4 \times 4$ & 1496 & 10 & yes & 3 & furan sand & $\mathrm{O}$ \\
\hline CW-12MW & $1 \times 8$ & 8 & 5.3 & $4 \times 5$ & 1584 & 10 & no & 1 & furan sand & $\mathrm{G}$ \\
\hline CW-12MW & $1 \times 8$ & 8 & 5.3 & $4 \times 5$ & 1521 & 10 & no & 2 & furan sand & $\mathrm{G}$ \\
\hline CW-12MW & $1 \times 8$ & 8 & 5.3 & $4 \times 4$ & 1588 & 4 & no & $0(3)^{*}$ & furan sand & $\mathrm{N}$ \\
\hline CW-12MW & $1 \times 8$ & 8 & 5.3 & $4 \times 4$ & 1579 & 4 & no & $0(3)^{*}$ & furan sand & $\mathrm{N}$ \\
\hline CW-12MW & $1 \times 8$ & 8 & 5.3 & $4 \times 4$ & 1571 & 4 & no & $0(3)^{*}$ & furan sand & $\mathrm{N}$ \\
\hline CW-12MW & $1 \times 8$ & 10 & 6.9 & $4 \times 5$ & 1558 & 10 & no & 1 & furan sand & $\mathrm{G}$ \\
\hline CW-12MW & $1 \times 8$ & 10 & 6.9 & $4 \times 5$ & 1558 & 10 & no & 1 & furan sand & $\mathrm{G}$ \\
\hline CW-12MW & $1 \times 8$ & 12 & 8.8 & $4 \times 5$ & 1584 & 10 & no & 3 & furan sand & G \\
\hline CW-12MW & $1 \times 8$ & 12 & 8.8 & $4 \times 5$ & 1521 & 10 & no & 5 & furan sand & $\mathrm{G}$ \\
\hline CW-12MW & $1 \times 8$ & 16 & 12.6 & $4 \times 4$ & 1560 & 7 & no & $2(3)^{*}$ & furan sand & $\mathrm{N}$ \\
\hline CW-12MW & $1 \times 8$ & 16 & 12.6 & $4 \times 4$ & 1552 & 8 & no & $2(3)^{*}$ & furan sand & $\mathrm{N}$ \\
\hline CW-12MW & $1 \times 8$ & 16 & 12.6 & $4 \times 4$ & 1541 & 9 & no & $4(4)^{*}$ & furan sand & $\mathrm{N}$ \\
\hline CZ-100 & $1 \times 8$ & 8 & 5.3 & $4 \times 5$ & 1594 & 10 & no & 1 & furan sand & $\mathrm{G}$ \\
\hline CZ-100 & $1 \times 8$ & 8 & 5.3 & $4 \times 5$ & 1579 & 10 & no & 1 & furan sand & G \\
\hline CZ-100 & $1 \times 8$ & 8 & 5.3 & $4 \times 4$ & 1459 & 7 & no & 0 & furan sand & W \\
\hline CZ-100 & $1 \times 8$ & 8 & 5.3 & $4 \times 4$ & 1455 & 7 & no & 0 & furan sand & W \\
\hline CZ-100 & $1 \times 8$ & 8 & 5.3 & $4 \times 4$ & 1451 & 7 & no & 0 & furan sand & $\mathrm{W}$ \\
\hline CZ-100 & $1 \times 8$ & 10 & 6.9 & $4 \times 5$ & 1572 & 10 & no & 1 & furan sand & G \\
\hline CZ-100 & $1 \times 8$ & 10 & 6.9 & $4 \times 5$ & 1572 & 10 & no & 1 & furan sand & $\mathrm{G}$ \\
\hline CZ-100 & $1 \times 8$ & 10 & 6.9 & $4 \times 5$ & 1551 & 10 & no & 1 & furan sand & $\mathrm{G}$ \\
\hline CZ-100 & $1 \times 8$ & 12 & 8.8 & $4 \times 5$ & 1594 & 10 & no & 1 & furan sand & $\mathrm{G}$ \\
\hline CZ-100 & $1 \times 8$ & 12 & 8.8 & $4 \times 5$ & 1579 & 10 & no & 1 & furan sand & $\mathrm{G}$ \\
\hline CZ-100 & $1 \times 8$ & 16 & 12.6 & $4 \times 6$ & 1432 & 14 & no & 0 & furan sand & W \\
\hline CZ-100 & $1 \times 8$ & 16 & 12.6 & $4 \times 6$ & 1444 & 12 & no & 0 & furan sand & $\mathrm{W}$ \\
\hline CZ-100 & $1 \times 8$ & 16 & 12.6 & $4 \times 6$ & 1448 & 11 & no & 0 & furan sand & W \\
\hline Monel-35-1 & $1 \times 8$ & 8 & 5.3 & $4 \times 5$ & 1428 & 5.7 & no & $0(1)^{*}$ & green sand & $\mathrm{T}$ \\
\hline Monel-35-1 & $1 \times 8$ & 8 & 5.3 & $4 \times 5.8$ & 1421 & 4.3 & no & $0(4)^{*}$ & green sand & $\mathrm{T}$ \\
\hline Monel-35-1 & $1 \times 8$ & 8 & 5.3 & $4 \times 5.7$ & 1421 & 4.9 & no & $0(4)^{*}$ & green sand & $\mathrm{T}$ \\
\hline Monel-35-1 & $1 \times 8$ & 16 & 12.6 & $4 \times 6.2$ & 1428 & 11 & no & $5(5)^{*}$ & green sand & $\mathrm{T}$ \\
\hline Monel-35-1 & $1 \times 8$ & 16 & 12.6 & $4 \times 6$ & 1428 & 6.4 & no & $5(5)^{*}$ & green sand & $\mathrm{T}$ \\
\hline Monel-35-1 & $1 \times 8$ & 16 & 12.6 & $4 \times 5.6$ & 1428 & 7.8 & no & $5(5)^{*}$ & green sand & $\mathrm{T}$ \\
\hline M-30C & $1 \times 8$ & 8 & 5.3 & $4 \times 5$ & 1608 & 10 & no & 1 & furan sand & $\mathrm{G}$ \\
\hline M-30C & $1 \times 8$ & 8 & 5.3 & $4 \times 5$ & 1558 & 10 & no & 1 & furan sand & $\mathrm{G}$ \\
\hline M-30C & $1 \times 8$ & 10 & 6.9 & $4 \times 5$ & 1589 & 10 & no & 1 & furan sand & $\mathrm{G}$ \\
\hline M-30C & $1 \times 8$ & 10 & 6.9 & $4 \times 5$ & 1589 & 10 & no & 1 & furan sand & $\mathrm{G}$ \\
\hline M-30C & $1 \times 8$ & 10 & 6.9 & $4 \times 5$ & 1561 & 10 & no & 2 & furan sand & $\mathrm{G}$ \\
\hline M-30C & $1 \times 8$ & 10 & 6.9 & $4 \times 5$ & 1561 & 10 & no & 1 & furan sand & $\mathrm{G}$ \\
\hline M-30C & $1 \times 8$ & 12 & 8.8 & $4 \times 5$ & 1608 & 10 & no & 1 & furan sand & $\mathrm{G}$ \\
\hline M-30C & $1 \times 8$ & 12 & 8.8 & $4 \times 5$ & 1558 & 10 & no & 2 & furan sand & $\mathrm{G}$ \\
\hline
\end{tabular}

$* \mathrm{X}$-ray levels in parentheses indicate ratings of under-riser shrinkage, which are not relevant to FD.

the liquidus $\left(T_{L}\right)$ and solidus* $\left(T_{S}\right)$ temperatures, which denote

*The term "solidus" is used here to denote the temperature at which the alloy is 100 pct solidified; $T_{S}$ can be very different from the equilibrium solidus temperature, e.g., it could be a ternary eutectic temperature. the beginning and end of solidification, respectively. Both of these temperatures are obtained from the mid-plate TC data (Figures 7(a) through 10(a)), because the end-plate TCs are subject to a significant conduction error, as is explained in more detail later. The liquidus temperature is determined 


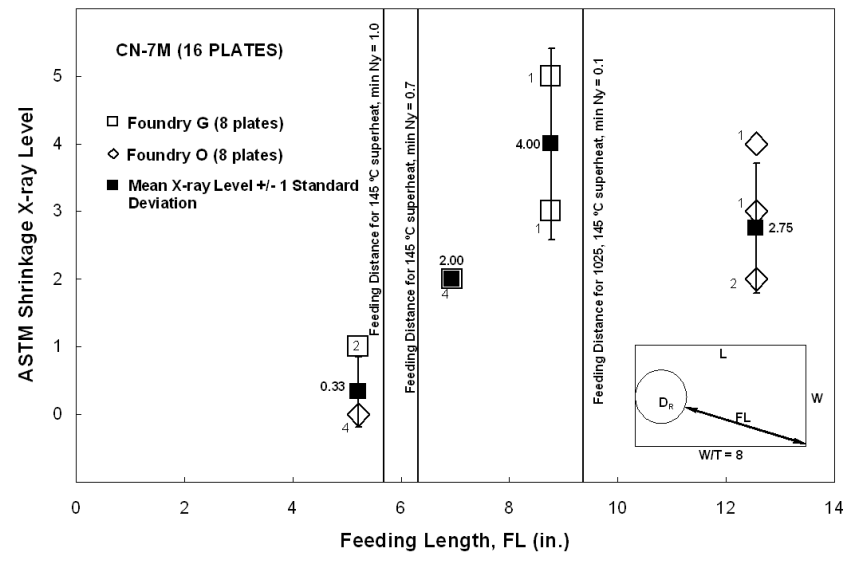

Fig. 3-Casting trial results: FL vs shrinkage X-ray level for CN-7M plates.

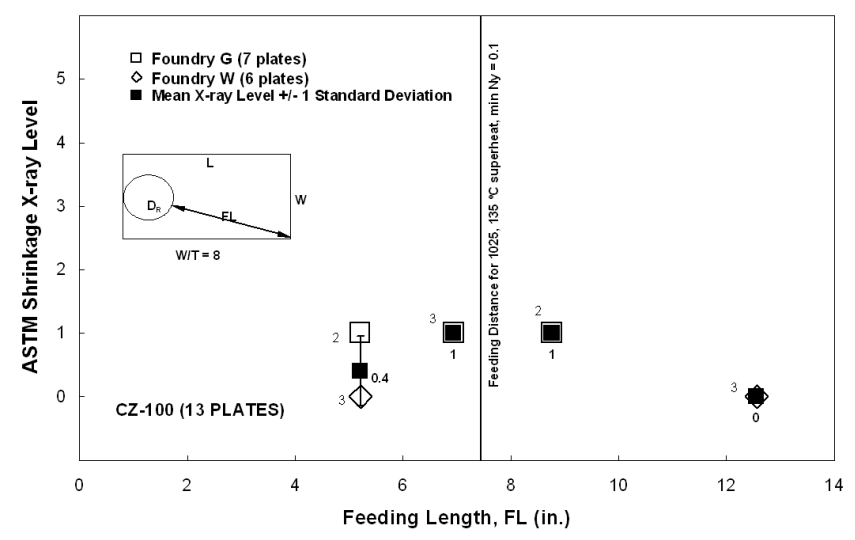

Fig. 4-Casting trial results: FL vs shrinkage X-ray level for CZ-100 plates.

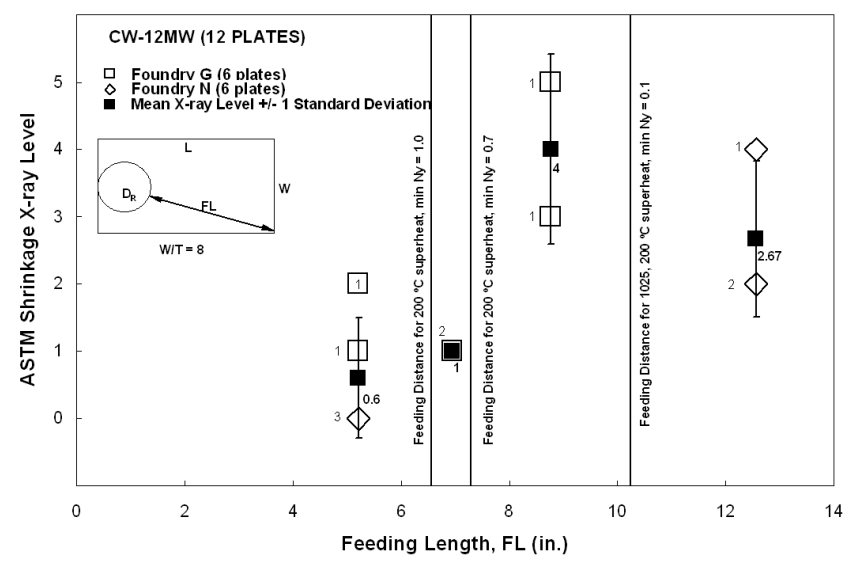

Fig. 5-Casting trial results: FL $v s$ shrinkage X-ray level for CW-12MW plates.

from a local peak in the cooling rate curve (for example, the left side of Figure 7(a)). Note that the cooling rate scale (the right side of the plot in Figure 7(a)) increases from top to bottom, so this peak in the cooling rate curve is actually a local minimum in the cooling rate, caused by the onset of latent heat release as solidification begins. The liquidus temperature can also be seen as a kink in the temperature curve, from a very steeply descending slope to a much shallower

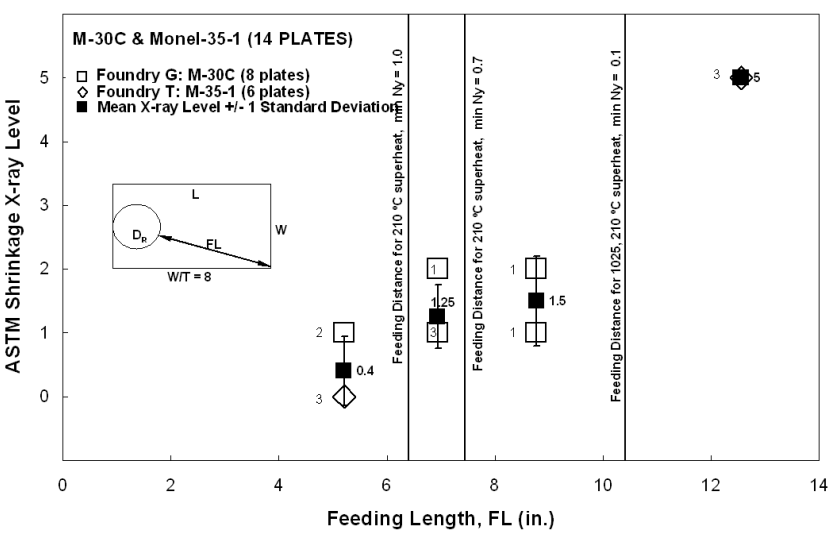

Fig. 6-Casting trial results: FL vs shrinkage X-ray level for M-35-1 and M-30C plates.

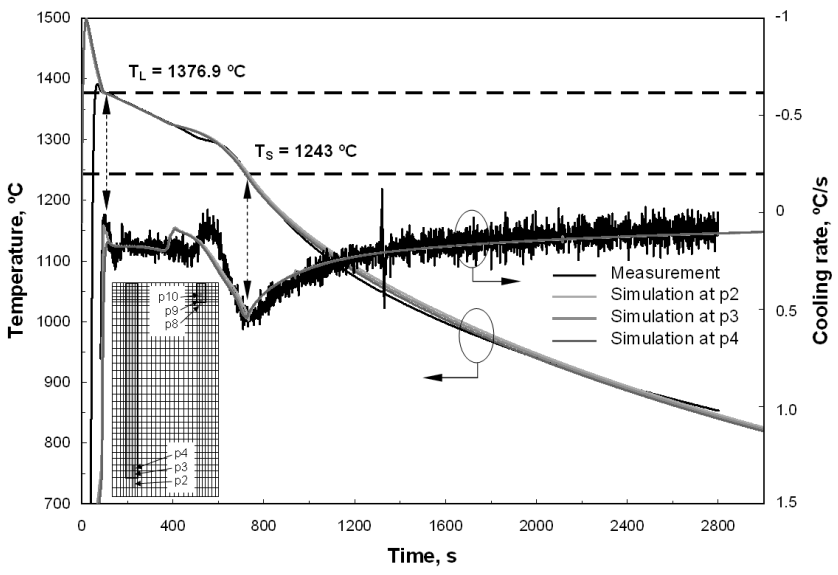

(a)

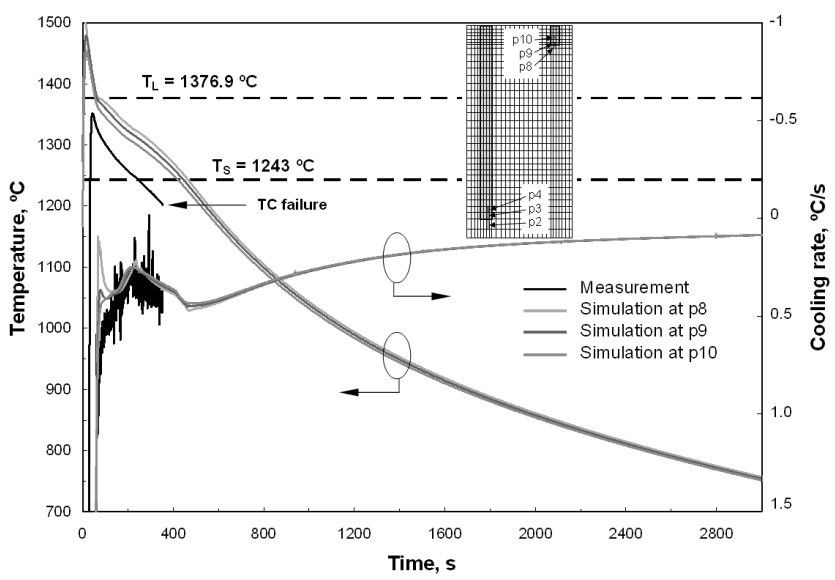

(b)

Fig. 7-Measured and simulated CZ-100 temperature and cooling rate curves for $(a)$ mid-plate TC and $(b)$ end-plate TC.

slope (the upper left of Figure 7(a)). For each of the four alloys, the minimum cooling rate corresponding to the liquidus temperature is indicated by a vertical dashed line with arrows on each end, in Figures 7(a) through 10(a). The liquidus temperature is given by the intersection of the vertical dashed line with the measured temperature curve, as indicated by a thick horizontal dashed line in each of the figures. 


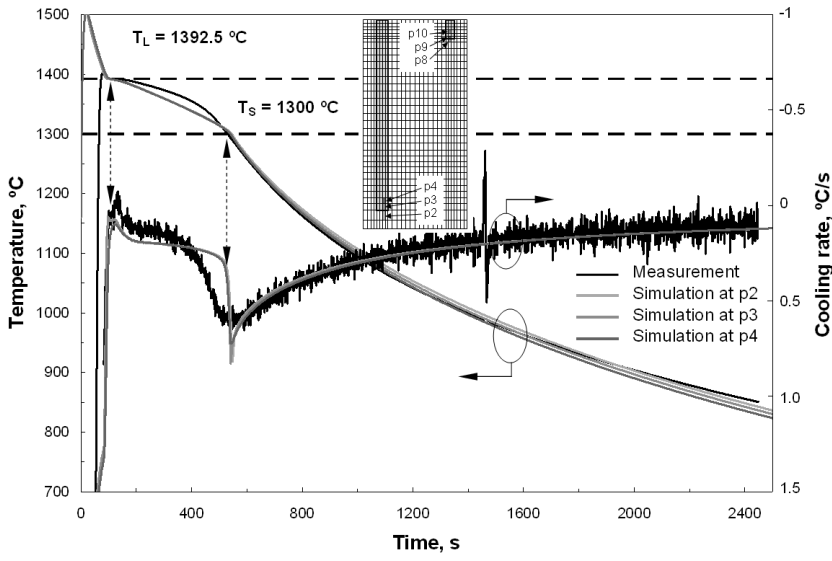

(a)

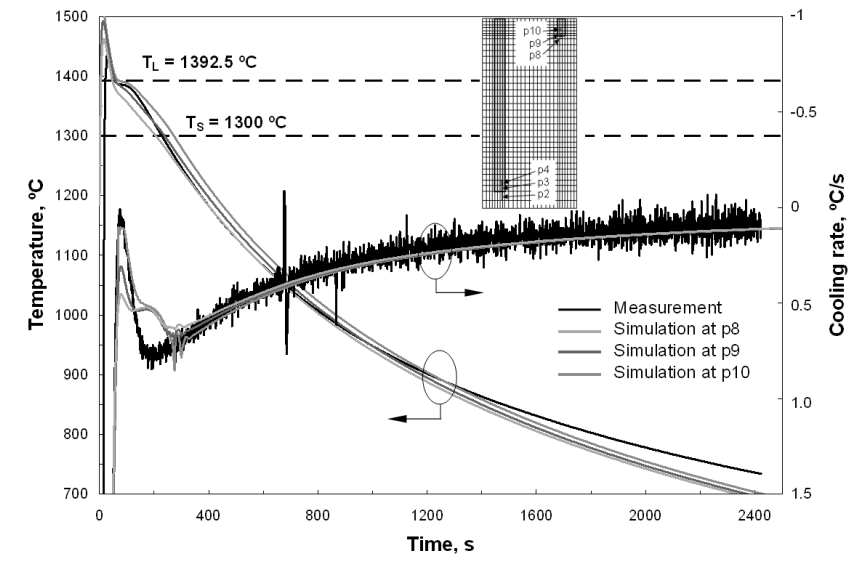

(b)

Fig. 8-Measured and simulated CN-7M temperature and cooling rate curves for (a) mid-plate TC and $(b)$ end-plate TC.

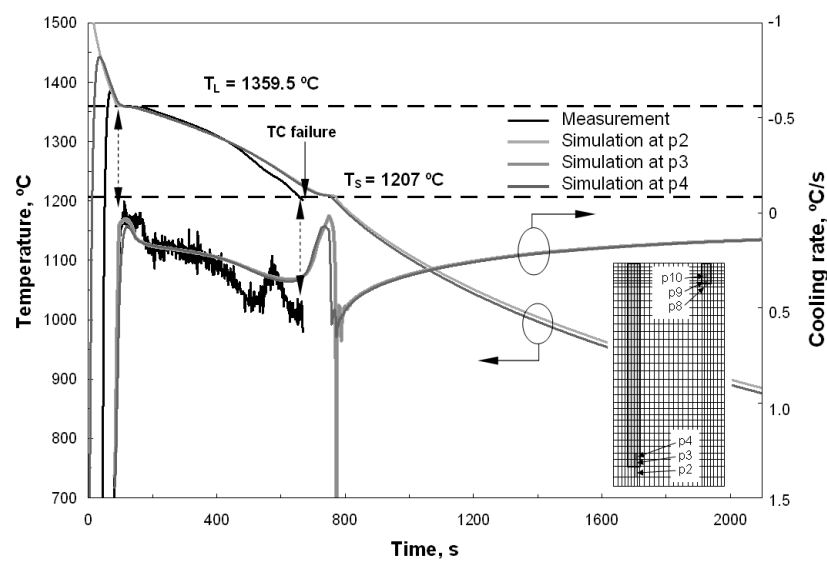

(a)

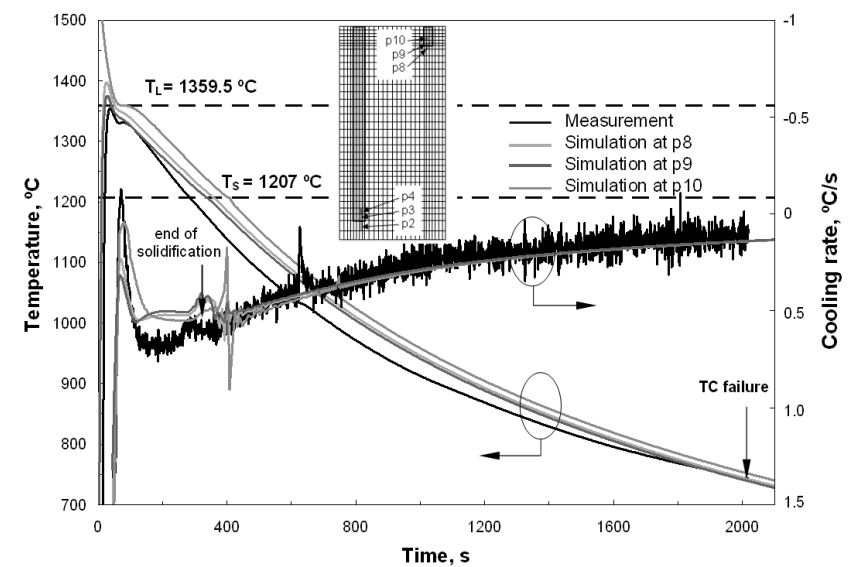

(b)

Fig. 9-Measured and simulated CW-12MW temperature and cooling rate curves for $(a)$ mid-plate TC and $(b)$ end-plate TC.

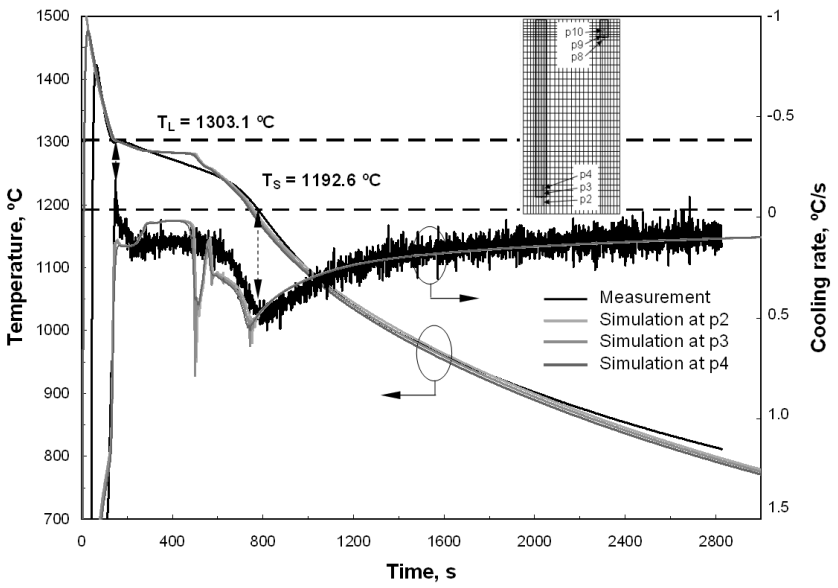

(a)

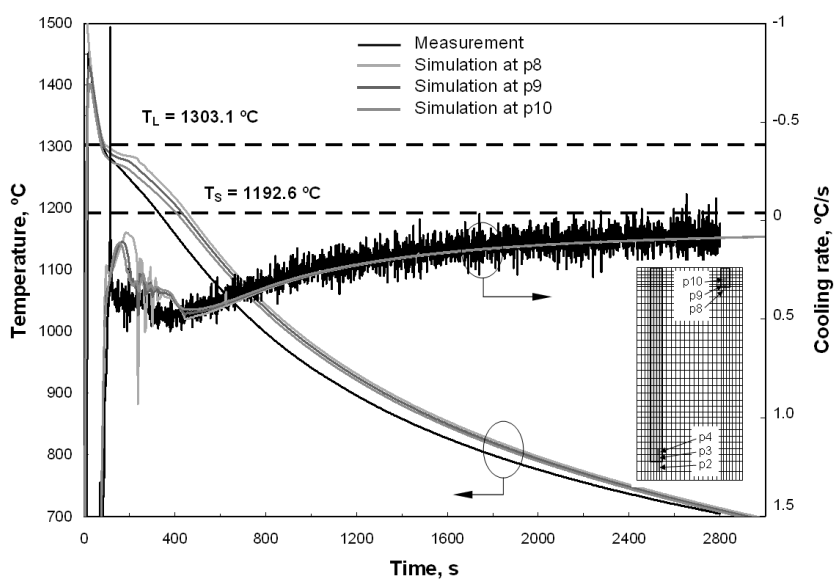

(b)

Fig. 10-Measured and simulated M-30C temperature and cooling rate curves for $(a)$ mid-plate TC and $(b)$ end-plate TC.

The solidus temperature is determined from the measured cooling rate and temperature curves in a similar manner. At the location of the solidus, the cooling rate curve shows a local trough. Again, because the cooling rate scale on the right of these figures increases from top to bottom, a local trough is actually a local maximum in the cooling rate, brought about by the end of latent heat release at the end of solidification. For each of the four alloys, the maximum cooling rate 


\begin{tabular}{|c|c|c|c|c|c|c|}
\hline & \multirow[b]{2}{*}{ Alloy } & \multirow[b]{2}{*}{$\begin{array}{c}\text { Phases Allowed } \\
\text { in JMatPro }\end{array}$} & \multirow[b]{2}{*}{$\begin{array}{l}\text { Liquidus } \\
\mathrm{T}_{\mathrm{L}}\left({ }^{\circ} \mathrm{C}\right) \\
\end{array}$} & \multicolumn{2}{|c|}{ Solidus } & \multirow[b]{2}{*}{$\begin{array}{c}\text { Latent Heat } \\
(\mathrm{J} / \mathrm{g})\end{array}$} \\
\hline & & & & $\mathrm{T}_{\mathrm{S}}\left({ }^{\circ} \mathrm{C}\right)$ & $\begin{array}{l}\text { Solidification } \\
\text { Cutoff (pct) }\end{array}$ & \\
\hline \multirow[t]{3}{*}{$\mathrm{CN}-7 \mathrm{M}$} & Measurement-TC data & & 1392.5 & 1300 & & \\
\hline & JMatPro: Measured G composition & all available phases & 1406.0 & 1192 & 2 & 200 \\
\hline & JMatPro: Adjusted G composition & all available phases & 1392.5 & 1300 & 15.5 & 174 \\
\hline \multirow[t]{3}{*}{ CZ-100 } & Measurement-TC data & & 1376.9 & 1243 & & \\
\hline & JMatPro: Measured G composition & $\begin{array}{l}\text { liquid, austenite (Ni } \\
\text { matrix), graphite }\end{array}$ & 1402.2 & 1277 & 2 & 270 \\
\hline & JMatPro: Adjusted G composition & $\begin{array}{l}\text { liquid, austenite (Ni } \\
\text { matrix), graphite }\end{array}$ & 1376.9 & 1243 & 5 & 261 \\
\hline \multirow[t]{4}{*}{ CW-12MW } & Measurement-TC data & & 1359.5 & 1207 & & \\
\hline & JMatPro: Measured G composition & all available phases & 1369.8 & 1112 & 2 & 219 \\
\hline & JMatPro: Adjusted G composition & all available phases & 1359.5 & 1207 & 6.7 & 209 \\
\hline & JMatPro: Measured N composition & all available phases & 1347.9 & 1188 & 6.7 & 215 \\
\hline \multirow[t]{3}{*}{ M-30C } & Measurement-TC data & & 1303.1 & 1193 & & \\
\hline & JMatPro: Measured G composition & $\begin{array}{l}\text { liquid, austenite (Ni } \\
\text { solid solution) }\end{array}$ & 1315.8 & 1106 & 2 & 245 \\
\hline & JMatPro: Adjusted G composition & $\begin{array}{l}\text { liquid, austenite (Ni } \\
\text { solid solution) }\end{array}$ & 1303.1 & 1193 & 2 & 245 \\
\hline M-35-1 & JMatPro: Measured T composition & $\begin{array}{l}\text { liquid, austenite (Ni } \\
\text { solid solution) }\end{array}$ & 1315.4 & 1186 & 2 & 227 \\
\hline
\end{tabular}

*All alloy compositions were simulated with a user-defined high-alloy material in JMatPro, which allowed the user to include in the composition all elements listed in Table I.

corresponding to the solidus temperature is indicated by another vertical dashed line with arrows on each end, in Figures 7(a) through 10(a). The location of the maximum cooling rate is obvious for all alloys, except for CW-12MW (Figure 9(a)). This can be attributed to the premature failure of the mid-plate TC in this casting. Nonetheless, it was possible to make a reasonable estimate of the location of the maximum cooling rate for this alloy by consulting the measured cooling rates for the end-plate TC (Figure 9(b)). For each alloy, the solidus temperature is again given by the intersection of the vertical dashed line with the measured temperature curve. The solidus temperatures are indicated also by thick horizontal dashed lines in Figures 7 through 10. All measured liquidus and solidus temperatures are summarized in Table III. The estimated uncertainties in the measured liquidus and solidus temperatures are $3{ }^{\circ} \mathrm{C}$ and $10{ }^{\circ} \mathrm{C}$, respectively.

The first step in bringing the measured and simulated temperatures into agreement was to modify the thermal conductivity of the liquid metal above the liquidus temperature in the simulation. This was done because the casting simulation neglects convection in the liquid. Convection significantly enhances cooling of the liquid metal early in the casting process, before solidification begins. After some trial and error, the liquid metal thermal conductivity at temperatures above the liquidus was multiplied by 2.5 . This value was chosen because it brought the simulation cooling rate before solidification into agreement with the experimental data. This can be clearly seen on the far left sides of Figures 7 through 10, from the excellent agreement in the steeply decreasing temperatures before the liquidus is reached.

Next, it was necessary to determine the effective thermal conductivity and other properties of the TCs themselves. The TCs were included in the casting simulations in order to model the effect of conduction losses on the TC readings. As shown in Figure 3, the TCs extended through the mold into the atmosphere, and it was noticed during the casting trials that the ends of the TC tubes were glowing red hot. Heat conduction away from the TC bead, along the tubes to the atmosphere, results in readings that are lower than the actual metal temperature would be at the location of the bead. One indication of this effect can be seen for the endplate TC readings in Figures 7(b) and 9(b): the measured end-plate temperatures never reach the liquidus temperature. There are many uncertainties involved in the thermal modeling of each TC. The exact location of the TC bead is not known, since the bead is inside a closed-end tube. Also, the thermal conductivity must account for many materials, including the ceramic tubes and the quartz tubes, as well as the air gaps present. Finally, due to discretization limits in the simulation, the entire cross-section of the TC must be represented by only a few control volumes, so it would be impossible to accurately represent the many materials that are in the TC. Due to all of these complexities, it was decided that the best course of action would be to choose a single, effective thermal conductivity for the entire TC arrangement. In addition, it was necessary to determine the location within the simulated TC to assign to the TC bead. This can be understood from the simulation grid arrangement inset into each figure, in Figures 7 through 10. This picture shows part of the top-view cross-section that cuts through the middle of the plate and TCs. The top edge of this grid picture is the end of the plate, where the TCs are inserted. The long TC that extends to the middle of the plate (midplate TC) is on the left, and the short TC that only extends a small distance into the plate (end-plate TC) is on the right. Considering the mid-plate TC, there are three cells (p2, p3, and $\mathrm{p} 4$ ) for which the temperatures predicted by the simulation are plotted in Figures 7(a) through 10(a). The first cell, p2, is actually outside of the TC (thus providing the actual metal temperature at this location), while both $\mathrm{p} 3$ and 
p4 are inside the TC. Notice that these three predicted temperature curves are very similar, which indicates that this region of the casting is relatively isothermal, and that conduction losses for the mid-plate TCs are small. On the other hand, the three predicted temperature curves for the end-plate TC (at locations p8, p9, and p10, in Figures 7(b) through 10(b)) show differences of up to $30^{\circ} \mathrm{C}$ at certain times. This indicates that the end-plate TC is indeed experiencing significant conduction losses, which is expected based on its location in the plate and on the small amount of sand mold between the plate and the atmosphere. Based on this information, the effective thermal conductivity was determined by bringing the simulation temperature results for the endplate TC into approximate agreement with the actual TC readings for the $\mathrm{CN}-7 \mathrm{M}$ experiment (Figure 8(b)). After some trial and error, an effective value of $10 \mathrm{~W} / \mathrm{m} \mathrm{K}$ was selected for the effective thermal conductivity of the TCs, which seems realistic. Other, less important effective properties selected for the TCs were a density of $2700 \mathrm{~kg} / \mathrm{m}^{3}$ and a specific heat of $1300 \mathrm{~J} / \mathrm{kg} \mathrm{K}$. These values were used in all subsequent casting simulations.

Another modification that was required to obtain agreement was a slight adjustment to the composition of the alloys. This was done in order to match the simulated liquidus temperatures from JMatPro with the measured values. Adjustment of the composition to obtain the measured liquidus temperature with JMatPro can be justified by the fact that there could be small inaccuracies in the measured compositions, that there may be local changes in the composition away from the originally measured values (due to macrosegregation), and that there may be some inaccuracies in the JMatPro thermodynamic database. The adjusted compositions are labeled "Simulation" in Table I and are based on the measured compositions from Foundry G (where all TC data were collected). Care was taken to keep the adjustment amounts for each element as small as possible. The adjustments are not unique, in that somewhat different adjustments could also produce agreement between the measured and predicted liquidus temperatures, but they are believed to be reasonable. An example of the effect of adjusting the chemistry on the simulated liquidus temperature is shown for CZ-100 in Figure 11(a). Note that the curves generated with the adjusted chemistry match the measured liquidus temperature. Comparing the two curves labeled " $2 \mathrm{pct}$ cutoff," it can be seen that the adjustment made to the composition of the CZ-100 alloy primarily causes a shift of the solid-fraction- $v s$-temperature curve to lower temperatures, while preserving the general shape of the solidification path curve. Table III lists the liquidus temperatures predicted by JMatPro for both the measured and the adjusted compositions.

After the liquidus temperatures were brought into agreement, a final adjustment was made in JMatPro to match the measured and predicted solidus temperatures. This was necessary because of the method used by JMatPro to model solidification. JMatPro employs a Scheil approach (infinitely fast diffusion in the liquid, no diffusion in the solid) for all elements except carbon and nitrogen, which are modeled with a lever-rule approach (infinitely fast diffusion in both the liquid and solid). This is done because carbon and nitrogen are fast-diffusing elements in the solid. The use of this approach requires the definition of a solid fraction cutoff; if no cutoff is specified, the JMatPro approach produces a solidification path that reaches a solid fraction of unity at a temperature that is too low. In addition, this cutoff can

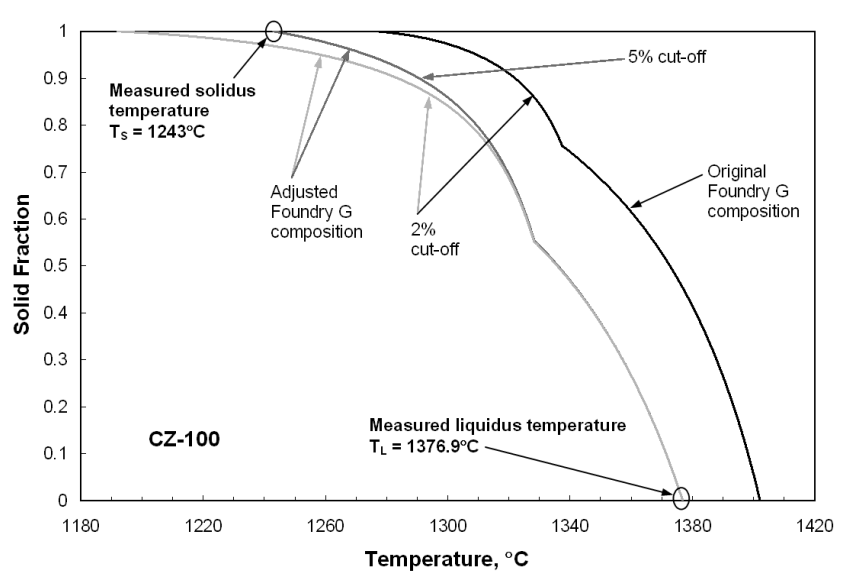

(a)

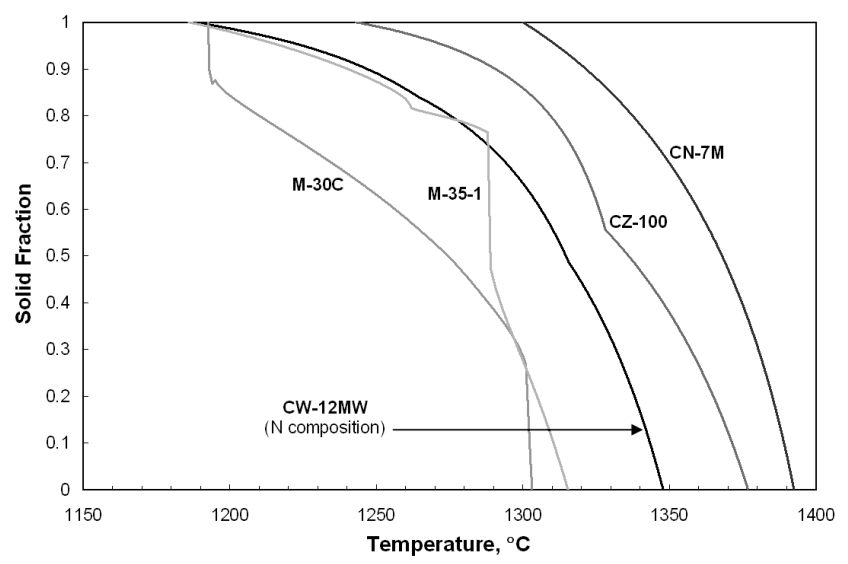

(b)

Fig. 11-Solidification paths calculated using JMatPro: (a) effect of composition adjustments and cutoff percentage changes for CZ-100 and $(b)$ final solidification paths for all high-nickel alloys.

account for the formation of certain phases or inclusions that are not predicted by JMatPro. When a cutoff value is specified in JMatPro, e.g., 2 pct, the simulation considers the material completely solidified when there is 2 pct liquid left (i.e., the material is 98 pct solidified). It rescales the solidification path such that it does not abruptly reach the solidus. An example of the effect that this has on the solidification path for CZ-100 is seen in Figure 11(a), where the solidification path produced by two different cutoff values ( 2 and 5 pct) is shown. A number of cutoff values were tried for each of the adjusted alloy compositions, until the predicted solidus matched the measured solidus. Table III lists the cutoff values obtained in this manner, as well as the latent heat values, for each alloy. For the baseline JMatPro simulations with the measured compositions, an arbitrary cutoff value of 2 pct is always used. For the adjusted compositions, the cutoff value reflects the matching of the measured and predicted solidus temperatures, as explained earlier. It can be seen that the cutoff values range from 2 to $15.5 \mathrm{pct}$ and that the different cutoffs shift the solidus temperature by up to about $100{ }^{\circ} \mathrm{C}$. The higher cutoff values cause significant changes in the solidification path that are unlikely to be very realistic. Nonetheless, it was decided that, for the purposes of the present study, it is more important to match the measured and predicted solidus temperatures than to attain an accurate solidification path. 
It should be mentioned that the solidus temperature calculated by JMatPro for a given alloy also depends on the phases that are predicted to form during solidification, in addition to the solid fraction cutoff. In most cases, the phases predicted by JMatPro are in agreement with the microstructures previously observed in as-cast specimens. ${ }^{[12]}$ As shown in Table III, for three of the alloys it was necessary to suppress within JMatPro certain phases that are predicted but not observed in as-cast specimens. For CZ-100, only liquid, austenite (Ni matrix), and graphite are allowed; for M-30C and M-35-1, only liquid and austenite (Ni solid solution) are allowed.

The final solidification paths predicted by JMatPro and used in the simulation of the casting trials are plotted for $\mathrm{CN}-7 \mathrm{M}$, CZ-100, CW-12MW, M-35-1, and M-30C, in Figure 11(b) (due to space limitations, the predicted thermal conductivities, specific heats, and densities as a function of temperature are not shown here). These curves were generated using the chemistries labeled as "Simulation" in Table I. In the case of CW-12MW, the curve shown in Figure 12 is for the Foundry

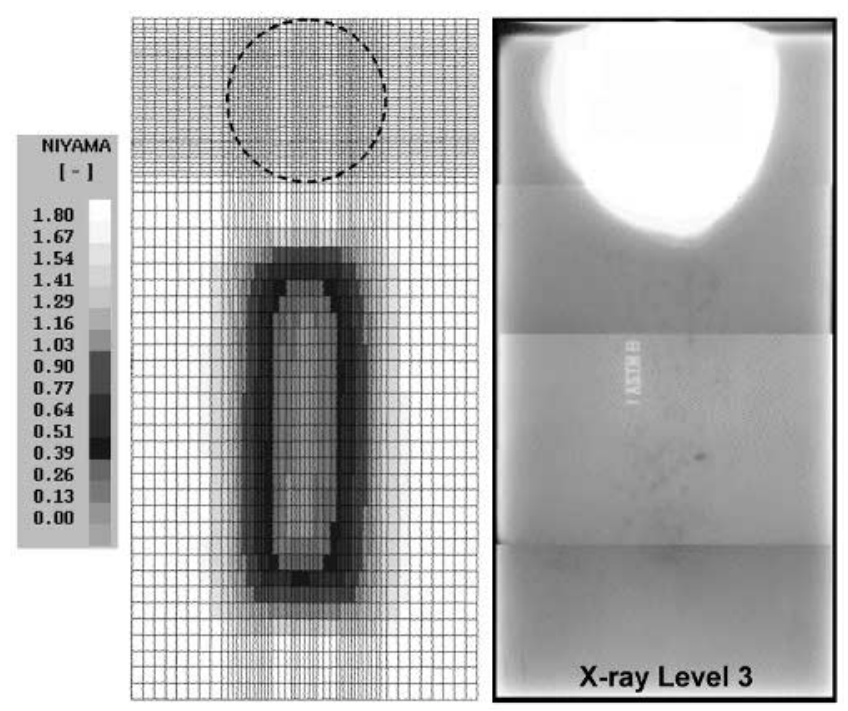

(a)

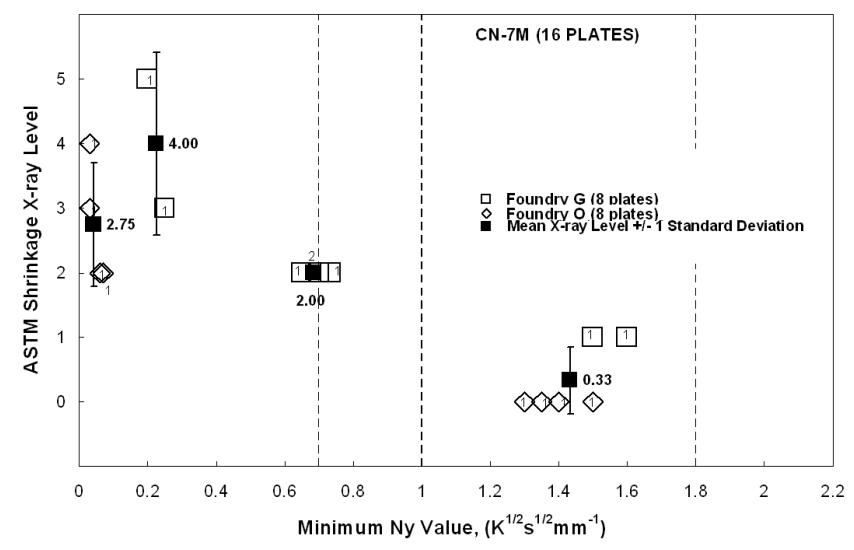

(b)

Fig. 12-Correlation of predicted Niyama criterion values with measured radiographic shrinkage indications for $\mathrm{CN}-7 \mathrm{M}$ : (a) comparison of predicted top view mid-thickness Niyama distribution (left) with radiograph (right) for a plate 1 in. $(2.54 \mathrm{~cm}) \times 8$ in. $(20.32 \mathrm{~cm}) \times 16$ in. $(40.64 \mathrm{~cm})$ and $(b)$ measured ASTM shrinkage X-ray levels as a function of predicted minimum Niyama values.
$\mathrm{N}$ chemistry, since the Foundry G chemistry is notably out of specification. This figure demonstrates why M-35-1 and M-30C were treated separately: although they have nearly the same liquidus and similar solidus temperatures, they have very different solidification paths. The predicted solid fraction curves for M-35-1 and M-30C exhibit very pronounced kinks that are unlikely to be realistic; however, it was verified that these kinks are not due to the formation of new phases. As mentioned earlier, the only solid phase that is allowed to form in these two alloys is austenite (Ni solid solution).

Returning now to Figures 7 through 10, generally good agreement is observed between the measured and predicted (by casting simulation) values of temperature and cooling rate for both the mid-plate and the end-plate TCs. The mid-plate TC comparisons (Figures 7(a) through 10(a)) show small deviations between the measured and predicted temperatures that occur over some portion of the solidification temperature interval. These deviations can be attributed to inaccuracies in the solidification path predicted by JMatPro, as discussed earlier. These inaccuracies cause the latent heat release in the casting simulation to be inaccurate. It was possible to make further, "manual" adjustments to the solidification path for each of the alloys (until the agreement between the measured and predicted temperatures is perfect), but this would have meant abandoning the use of JMatPro for obtaining the properties altogether. The end-plate TC comparisons (Figures 7(b) through 10(b)) are also good, except that the conduction error appears to be underestimated for at least two of the alloys (Figures 7(b) and 10(b)). Further adjustments to the TC effective thermal conductivity in some of the simulations would have been possible, but the present choice produces sufficiently good overall agreement. Note from Figure 9(b) that accounting for the conduction error in the simulations, through the inclusion of the TCs, is able to reproduce approximately the measured effect that the end-plate TC does not reach the liquidus temperature.

In summary, the use of the properties predicted by JMatPro in the simulation of the casting trials results in reasonably good agreement with the measured temperatures. As described in this section, several adjustments to both the casting simulation and the property prediction were necessary to attain this agreement. Improvements in the solidification path predictions by JMatPro appear to be warranted for at least some of the alloys investigated here. However, since it was possible to match the measured and predicted liquidus and solidus temperatures closely, it is believed that the Niyama criterion predictions presented in Section IV are reasonably accurate.

\section{CASTING TRIAL SIMULATIONS AND CORRELATION WITH RADIOGRAPHIC MEASUREMENTS}

Based on the information collected during the plate-casting trials, and using the solidification path and material property data for each alloy described in Section III, MAGMASOFT simulations were performed for each plate listed in Table II for which unique casting data are available. The simulations of the plate-casting trials provided the distribution of the Niyama criterion $(N y)$ throughout the castings. The Niyama criterion ${ }^{[13]}$ is a local thermal parameter defined as $G / \sqrt{\dot{T}}\left[\mathrm{~K}^{1 / 2} \mathrm{~s}^{1 / 2} \mathrm{~mm}^{-1}\right]$, where $G$ is the temperature gradient and $\dot{T}$ is the cooling rate. ${ }^{[2]}$ 
The Niyama criterion is evaluated during the simulation, when the temperature in a computational cell reaches a critical value near the end of solidification [i.e., $\left.T_{S}+0.1\left(T_{L}-T_{S}\right)\right]$. The close proximity of this critical temperature to $T_{S}$ is the reason why it is important to match the measured and predicted solidus temperatures closely, as described earlier. As in the previous work by the present authors, ${ }^{[2-5]}$ the Niyama criterion predictions are correlated with the X-ray shrinkage indications. Generally, a smaller Niyama value corresponds to a higher probability of shrinkage porosity occurring in that region of the plate, as shown in this section.

Figures 12(a) through 14(a) show examples of comparisons between predicted Niyama distributions and X-ray results for the $\mathrm{CN}-7 \mathrm{M}, \mathrm{CW}-12 \mathrm{MW}$, and $\mathrm{M}-35-1 / \mathrm{M}-30 \mathrm{C}$ alloys, respectively. No comparison is shown for the CZ-100 alloy, since all CZ-100 plates were found to be radiographically sound (Figure 4). All three figures correspond to plates 1 in. $(2.54 \mathrm{~cm}) \times 8$ in. $(20.3 \mathrm{~cm}) \times 16$ in. $(40.6 \mathrm{~cm})$ in size. The Niyama distributions are top views, cut at the mid-plate thickness. Good correspondence is observed

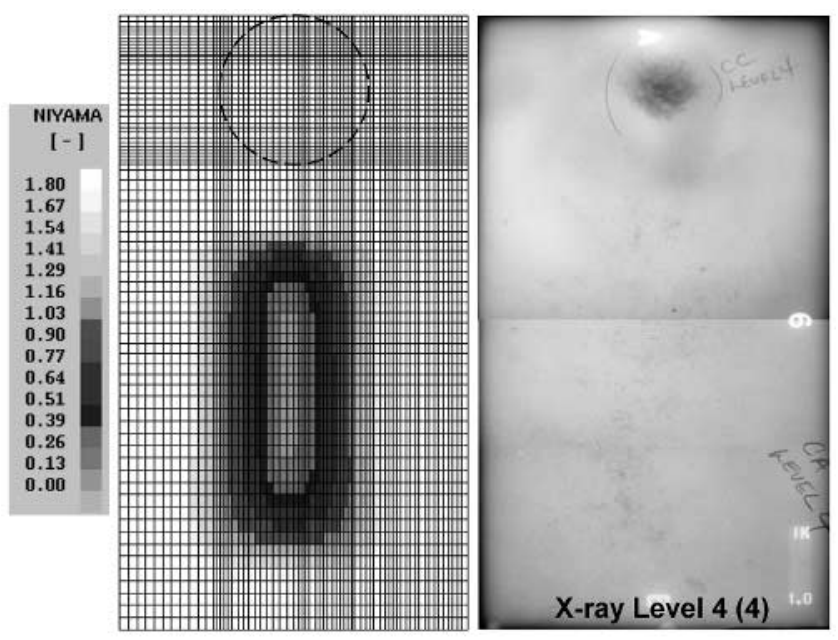

(a)

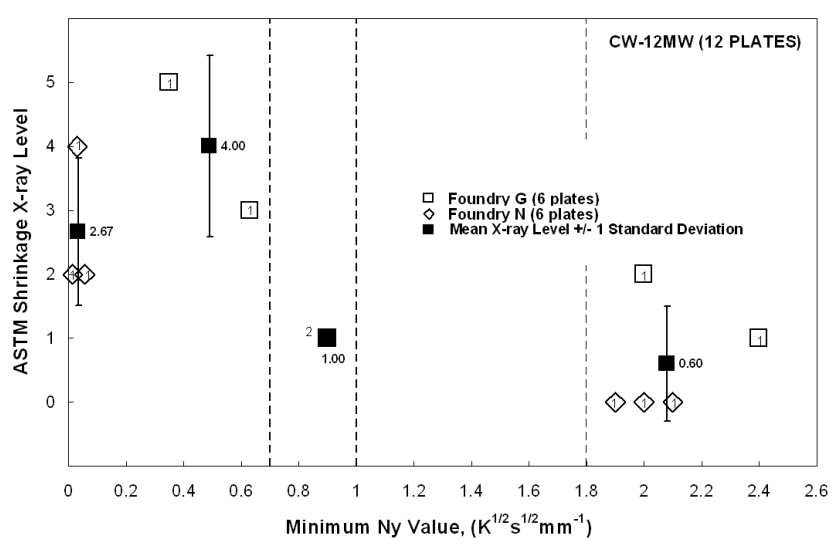

(b)

Fig. 13-Correlation of predicted Niyama criterion values with measured radiographic shrinkage indications for CW-12MW: (a) comparison of predicted top view mid-thickness Niyama distribution (left) with radiograph (right) for a plate 1 in. $(2.54 \mathrm{~cm}) \times 8$ in. $(20.32 \mathrm{~cm}) \times 16$ in. $(40.64 \mathrm{~cm})$ and $(b)$ measured ASTM shrinkage X-ray levels as a function of predicted minimum Niyama values. between the shrinkage indications on the X-ray and the region where Niyama values below approximately 1.0 are predicted. Regions with Niyama values above 1.0 are generally radiographically sound for all three alloys. Figure 13(a) (CW$12 \mathrm{MW}$ ) shows a shrinkage indication directly below the riser, while the Niyama values in this region are all above 1.8. This discrepancy can be attributed to the simulation predicting a riser pipe that is not as deep as the pipe the casting trials produced. Indeed, Figure 14(a) (M-35-1) shows lower Niyama values below the riser, which coincide with a level 5 indication on the X-ray. While these comparisons show a good correspondence between the locations of the shrinkage indications and low Niyama values, a more quantitative correlation between the predicted Niyama criterion values and the measured X-ray levels is developed.

The predicted minimum Niyama values for all casting trial plates are summarized in Figure 15 as a function of the FL. Again, the FL should not be confused with the FD; the FL is simply the length to be fed, as illustrated in the inset in Figure 15. Even though the results correspond to
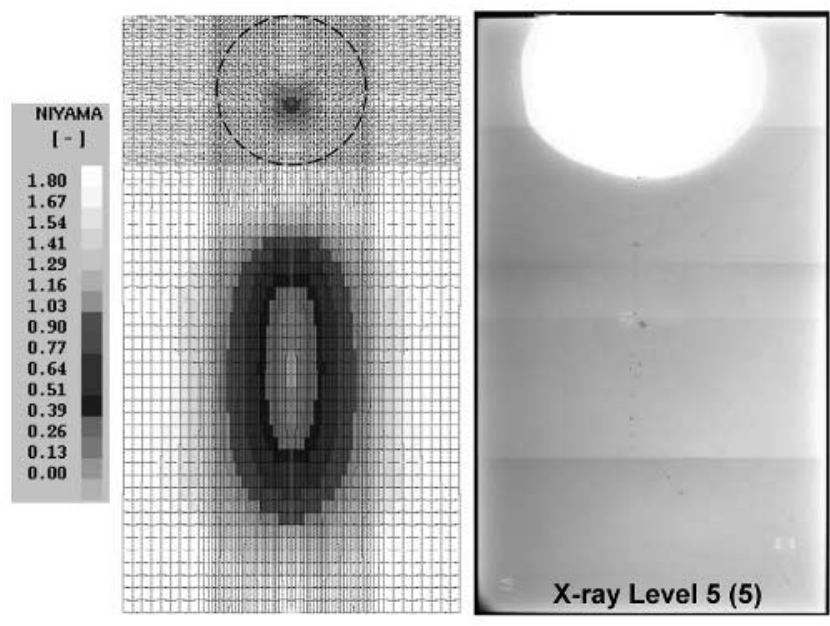

(a)

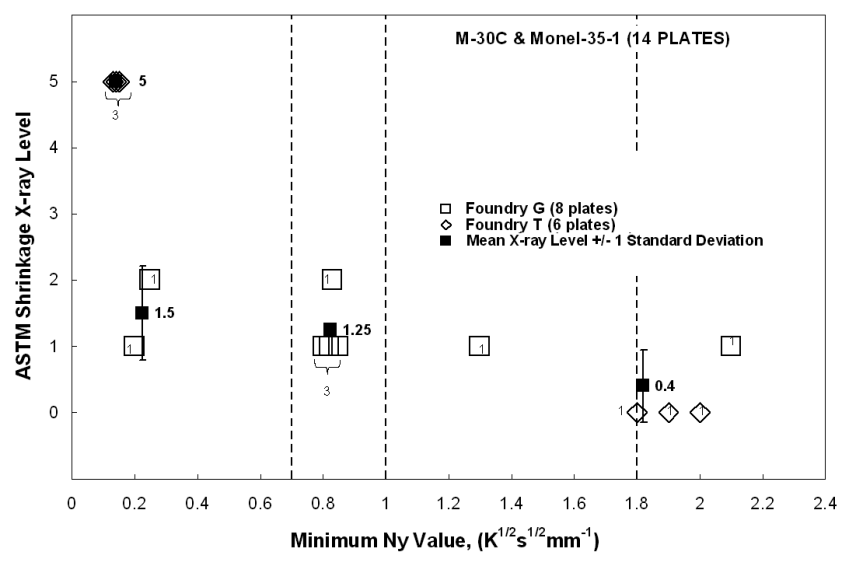

(b)

Fig. 14-Correlation of predicted Niyama criterion values with measured radiographic shrinkage indications for M-35-1/M-30C: (a) comparison of predicted top view mid-thickness Niyama distribution (left) with radiograph (right) for a plate 1 in. $(2.54 \mathrm{~cm}) \times 8$ in. $(20.32 \mathrm{~cm}) \times 16$ in. $(40.64 \mathrm{~cm})$ M-35-1 and $(b)$ measured ASTM shrinkage X-ray levels as a function of predicted minimum Niyama values. 


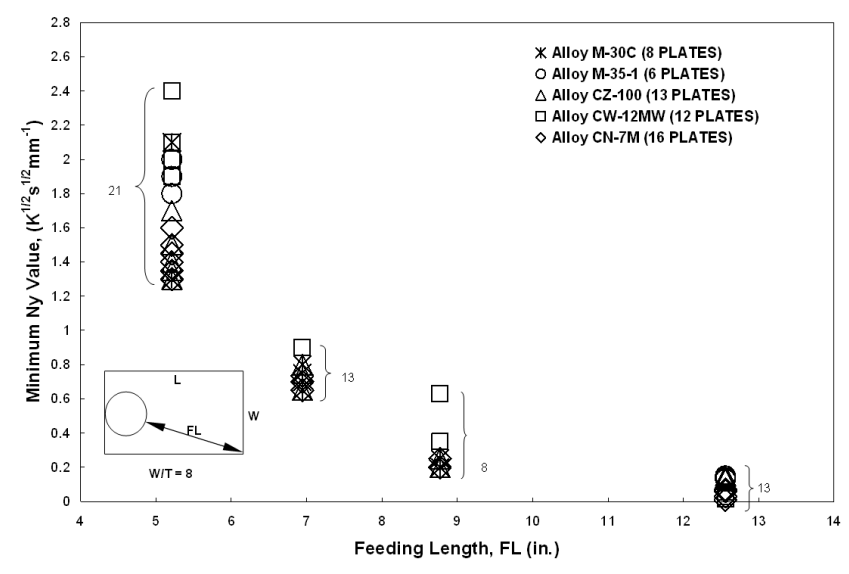

Fig. 15-The FL vs minimum Niyama value for the simulations of all casting trial plates.

five different high-Ni alloys, the minimum Niyama values show the same trend: they decrease with increasing FL. A very similar trend was observed in similar studies of C\&LA and high-alloy steels ${ }^{[2-5]}$ by the present authors, but a direct comparison cannot be made because the plate lengths and width/thickness $(W / T)$ ratios were different.

A quantitative relation between the measured ASTM shrinkage X-ray level and the predicted minimum Niyama value is now established, by eliminating the FL as a variable between the plots in Figures 3, 5, 6, and 15. Figures 12(b), 13(b), and 14(b) show the measured X-ray levels vs the predicted minimum Niyama values for the CN-7M, CW-12MW, and M30C/M-35-1 alloys, respectively. It can be seen that the X-ray level increases with decreasing minimum Niyama value. Minimum Niyama values of less than about 0.7 always correspond to radiographically unsound castings with X-ray levels of 2 and above. The transition between levels 2 and 1 (at $\mathrm{Ny}_{\min }=$ 0.7 ) is indicated in Figures 12(b), 13(b), and 14(b) as a vertical dashed line. A minimum Niyama value of 1.0 (again, indicated in Figures 12(b), 13(b), and 14(b) as a vertical dashed line) corresponds approximately to the transition between X-ray levels 1 and 0 . In other words, plates with a minimum Niyama value above 1.0 are, on the average, radiographically sound. A very conservative minimum Niyama value of 1.8 (again, indicated in Figures 12(b), 13(b), and 14(b) as a vertical dashed line) may be chosen to correspond to plates that have an even higher probability of being sound. These observations are true for all three alloys. Here, it should be kept in mind that the uncertainty in assigning an X-ray level to a casting section according to the ASTM standard is about \pm 0.7 for X-ray level 0 and at least \pm 1.5 for higher X-ray levels. ${ }^{[10]} \mathrm{A}$ minimum Niyama value of 0.7 is chosen in the following as the base case value for the simulations used to develop the FD rules for the high-nickel alloys. However, it is shown here how simple multipliers can be used to adapt the rules to any other minimum Niyama criterion value, such as 1.0 or 1.8 , depending on the desired radiographic soundness levels.

\section{FEEDING DISTANCE RULES}

Using the correlation between the minimum Niyama value and the radiographic soundness level established in Section IV, the results of casting simulations for different geometries and conditions were correlated to arrive at general FD rules, in the same manner as in References 2 through 5. Rules were developed only for the alloys CN-7M, CW-12MW, and M$30 \mathrm{C} / \mathrm{M}-35-1$, since the casting trials for the CZ-100 alloy always produced sound plates (Figure 4).

A large number of casting simulations were performed for rectangular top-risered plates where the width, $W$, and thickness, $T$, of the plates were varied. Starting from an arbitrarily large value, the length, $L$, of a plate of a given width and thickness was reduced until the minimum Niyama value that is predicted near the center of the plate was equal to 0.7 (with the Niyama values at all other locations in the plate being greater than 0.7 ). The FD is then given by the distance from the edge of the riser, along the diagonal, to the furthest point in this plate. Also, the riser-zone length, RZL, is the distance from the riser to the location of the minimum Niyama value, and the end-zone length, EZL, is the distance from the end of the plate (opposite to the riser) to the location of the minimum Niyama value. All of these lengths are illustrated in the insets in Figure 16. More explanations regarding FD, RZL, and EZL, and their use in risering castings, can be found in References 2 through 5. Simulations were performed for plate thicknesses, $T$, ranging from 1 in. $(2.54 \mathrm{~cm})$ to 12 in. $(30.5 \mathrm{~cm})$ and width-to-thickness ratios, $W / T$, ranging from 1 to 15 . In order for the simulation results to be compatible with the base case conditions used for the low- and high-alloy steel feeding rules, ${ }^{[2-5]}$ all simulations used a PUNB (furan) sand mold and a $60{ }^{\circ} \mathrm{C}$ pouring superheat. Again, it is shown here how simple multipliers can be used to adapt the rules to other mold sands and more realistic superheats.

The results of the simulations are shown as symbols in Figures 16(a) through (c) for the CN-7M, CW-12MW, and M-30C/M-35-1 alloys, respectively. All lengths are normalized by the plate thickness, $T$. It can be seen that the normalization results in $F D / T, R Z L / T$, and $E Z L / T$ being essentially independent of the thickness $T$, at a given $W / T$ ratio. The thick lines in the figures are best fits to the simulation results. For comparison, $F D / T$ as a function of $W / T$ for AISI 1025 steel $^{[3]}$ is included in the plots as a thin line. This thin line represents the base case FD rule developed in Reference 3 and is given by the following polynomial:

$$
\begin{aligned}
\left(\frac{\mathrm{FD}}{T}\right)_{\text {base case }}= & -4.29 \times 10^{-4}\left(\frac{W}{T}\right)^{4}+0.0174\left(\frac{W}{T}\right)^{3} . \\
& -0.266\left(\frac{W}{T}\right)^{2}+1.99\left(\frac{W}{T}\right)+1.97
\end{aligned}
$$

Equation [1] is accurate up to $W / T=15$, beyond which $F D / T$ has a constant value of 9.0. It gives the simple end-effect (i.e., no chill) FD for a plate made of AISI 1025 steel, cast in a furan sand mold with a pouring superheat of $60{ }^{\circ} \mathrm{C}$. In the development of this FD rule for C\&LA steel, a minimum Niyama value of 0.1 was established as the critical value that demarcates the transition between radiographically sound and unsound plates. ${ }^{[2]}$ With the help of Eq. [1], the FD for other alloys, casting conditions, and soundness levels can be obtained through the use of multipliers, $C$, as ${ }^{[3,5]}$

$$
\begin{aligned}
\left(\frac{\mathrm{FD}}{T}\right)_{\text {different conditions }} & =\left(\frac{\mathrm{FD}}{T}\right)_{\text {base case }} \times C_{\text {alloy }} \times C_{\text {Niyama }} \\
\times & C_{\text {sand mold }} \times C_{\text {cooling conditions }} \times C_{\text {superheat }}
\end{aligned}
$$




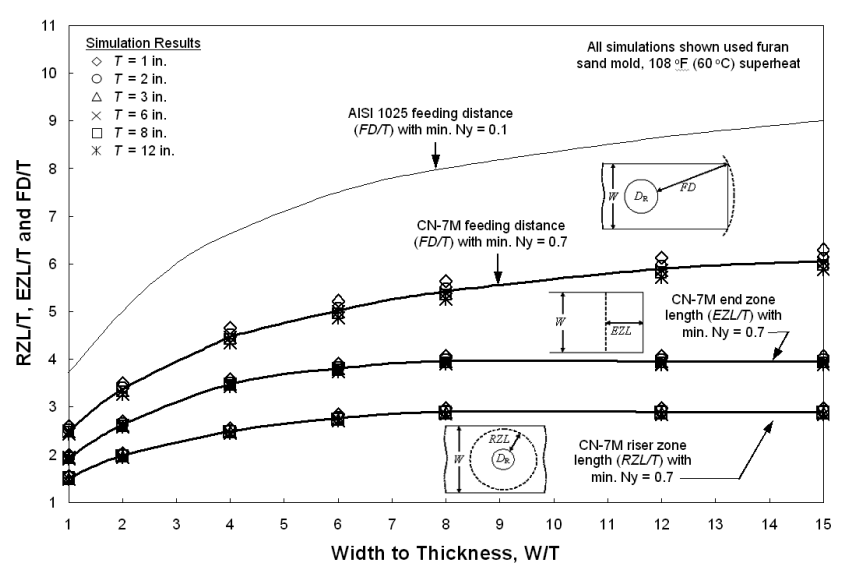

(a)

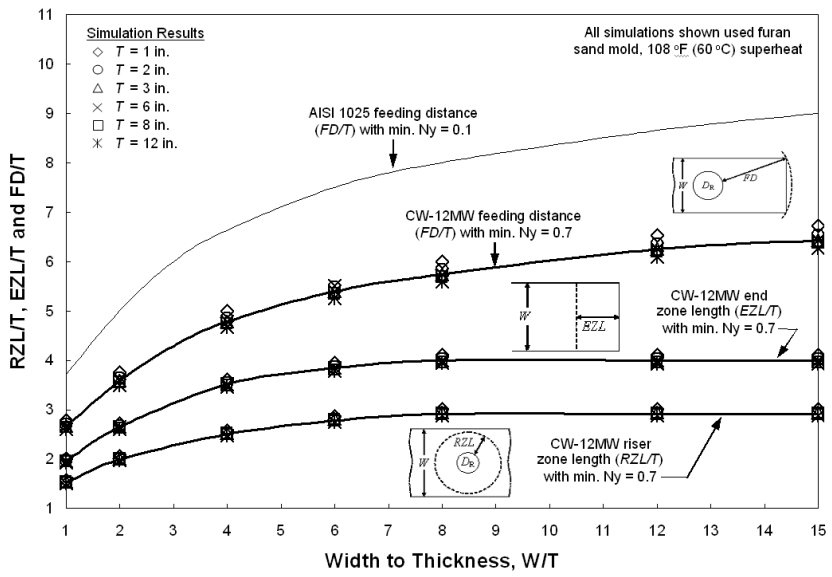

(b)

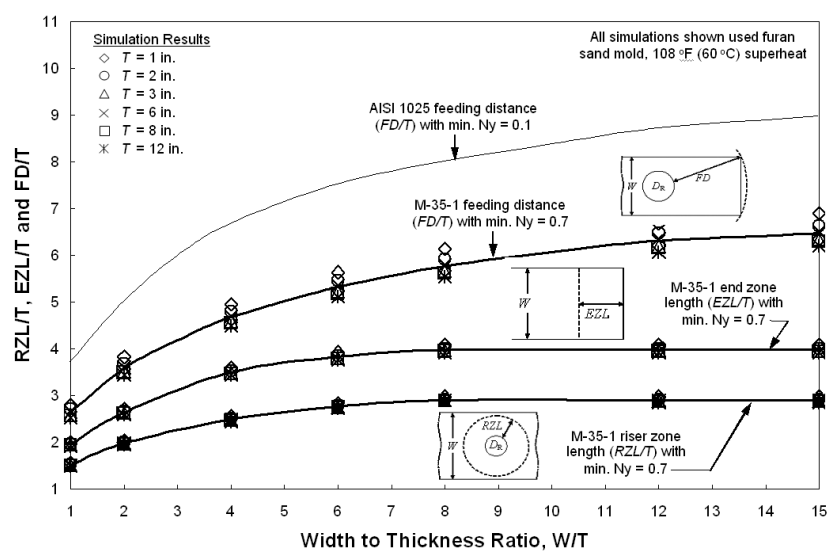

(c)

Fig. 16-Feeding rule development for (a) CN-7M, (b) CW-12MW, and (c) M-35-1: RZL, EZL, and FD, all normalized by the thickness $T$, as a function of $W / T$, together with simulation results (symbols) for various thicknesses.

Values for all multipliers were obtained through numerous additional simulations, and the results are listed in Table IV. The multipliers $C_{\text {sand mold }}, C_{\text {cooling conditions, }}$, and $C_{\text {superheat }}$ were verified to be identical to the ones for the C\&LA and highalloy steels. ${ }^{[3,4]}$ As an example of the effect of these multipliers, an end chill extends the FD by 19 pct $\left(C_{\text {cooling conditions }}=\right.$ 1.19 for end chill, as in Table IV). More detail on the use of these multipliers can be found in References 3 through 5.

As can be seen from Table IV, the multipliers $C_{\text {alloy }}$ for the high-nickel alloys, obtained in this study, range from 0.925 to 0.979 . The closeness of these multipliers to unity is somewhat misleading. They must always be used together with the appropriate minimum Niyama value multiplier, $C_{\text {Niyama }}$, in Table IV. For example, in order to obtain radiographically sound high-nickel alloy castings, a value of $C_{\text {Niyama }}=0.66$, corresponding to a minimum Niyama value of 1.0 (Table IV), must be used in Eq. [2] together with the appropriate $C_{\text {alloy. }}$ Hence, with all other conditions and the soundness level the same, the FDs for high-nickel alloys are smaller than for AISI 1025 steel by a factor between $0.925 \times$ $0.66=0.61$ and $0.979 \times 0.66=0.65$. Since the simulations in Figure 16 are for a minimum Niyama value of 0.7 , the thick lines representing $F D / T$ for the high-nickel alloys in these figures are given by Eqs. [1] and [2], with $C_{\text {Niyama }}=$ 0.73 and the appropriate $C_{\text {alloy }}$ from Table IV. This separation of the alloy and the minimum Niyama value effects through the use of two multipliers ( $C_{\text {alloy }}$ and $C_{\text {Niyama }}$, respectively) is of advantage because the $C_{\text {Niyama }}$ values are valid for all alloys, including C\&LA and high-alloy steels. ${ }^{[3,4]}$ Hence, $C_{\text {Niyama }}$ can be used to obtain FDs for different soundness levels, while keeping all other conditions the same.

The FD rules established through these simulations are now tested by comparing them to the experimental platecasting results in Figures 3 through 6 . The $F D$ obtained from Eqs. [1] and [2] and the multipliers in Table IV are indicated in these figures as vertical lines. Since the pouring superheat varied from plate to plate (Table II), a $C_{\text {superheat }}$ is interpolated from Table IV according to the average superheat in the casting trials for each alloy $\left(e . g ., 145^{\circ} \mathrm{C}\right.$ for the $\mathrm{CN}-7 \mathrm{M}$ plates). Focusing first on Figure 3 for the CN-7M alloy, it can be seen that the vertical line representing the FD for a minimum Niyama value of 1.0 indeed separates the radiographically sound from the unsound plates (transition between X-ray levels 1 and 0 ). The FD for a minimum Niyama value of 0.7 , also indicated in Figure 3 as a vertical line, approximately corresponds to an X-ray level between 1 and 2, as expected. Note that the FD for AISI 1025 steel in Figure 3 is almost 2 in. $(5.08 \mathrm{~cm})$ longer than the one for $\mathrm{CN}-7 \mathrm{M}$ (with $\mathrm{Ny}_{\min }=1.0$ ), and that the $\mathrm{CN}-7 \mathrm{M}$ plates cast with approximately that FL are very unsound. The same observations can be made for the CW-12MW and M-30C/M35-1 alloys in Figures 5 and 6, respectively. Since all CZ-100 
Table IV. Multipliers Used to Apply Base Case Feeding Rules to Other Conditions*

\begin{tabular}{lcc}
\hline Casting Parameter & $\begin{array}{c}\text { Condition } \\
\text { Description }\end{array}$ & $\begin{array}{c}\text { Multiplication } \\
\text { Factor, } C\end{array}$ \\
\hline Sand Mold Material & furan & 1 \\
$\left(C_{\text {sand mold }}\right)$ & green sand & 1.09 \\
& zircon & 0.96 \\
chromite & 0.88 \\
Cooling Conditions & end effect & 1 \\
$\left(C_{\text {cooling conditions }}\right)$ & end chill & 1.19 \\
& drag chill & 0.95 \\
High-Nickel Alloy $\left(C_{\text {alloy }}\right)$ & $\mathrm{CW}-12 \mathrm{MW}$ & 0.979 \\
(use with multiplier for & $\mathrm{M}-35-1$ and $\mathrm{M}-30 \mathrm{C}$ & 0.976 \\
$N y_{\text {min }}=1.0$ for & $\mathrm{CN}-7 \mathrm{M}$ & 0.925 \\
radiographically sound $)$ & & \\
Superheat $\left(C_{\text {superheat }}\right)$ & $30{ }^{\circ} \mathrm{C}$ & 0.94 \\
& $60{ }^{\circ} \mathrm{C}$ & 1 \\
& $90{ }^{\circ} \mathrm{C}$ & 1.06 \\
& $120^{\circ} \mathrm{C}$ & 1.12 \\
& $150{ }^{\circ} \mathrm{C}$ & 1.18 \\
Minimum Niyama Value, & $250{ }^{\circ} \mathrm{C}$ & 1.38 \\
$N y_{\text {min }}\left(C_{\text {Niyama }}\right)$ & 0.1 & 1 \\
& 0.2 & 0.90 \\
& 0.3 & 0.84 \\
& 0.7 & 0.73 \\
& 1.0 & 0.66 \\
& 1.8 & 0.56 \\
\hline
\end{tabular}

*Base case conditions are for AISI 1025 steel and are listed with the multiplier $C=1$.

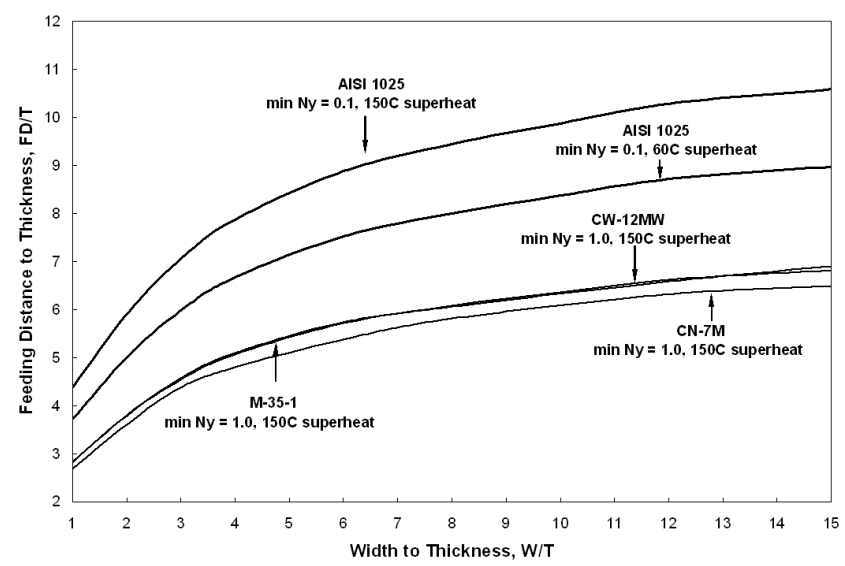

Fig. 17-Comparison of FD curves for CN-7M, CW-12MW, and M-35-1 with the one for AISI 1025.

plates cast in the present trials are sound and no feeding rules were developed for this alloy, Figure 4 only shows the AISI 1025 steel FD and it can be seen to be unrelated to the measured X-ray levels. In summary, these comparisons clearly establish the accuracy of the present high-nickel FD rules, at least for the conditions of the casting trials performed within the course of this study.

Finally, a comparison between the high-nickel alloy FD developed in this study and the AISI 1025 steel FDs ${ }^{[3]}$ is presented in Figure 17, as a plot of $F D / T v s W / T$. In this figure, the lines for both classes of alloys correspond to radiographically sound plates $\left(\mathrm{Ny}_{\min }=1.0\right.$ for the high-nickel alloys and 0.1 for AISI 1025 steel). It can be seen that the FDs for the high-nickel alloys are considerably shorter than those for lowalloy steel, as noted earlier. The figure also illustrates the important effect of pouring superheat. A typical superheat for AISI 1025 steel is $60{ }^{\circ} \mathrm{C}$, whereas for the high-nickel alloys it is as high as $150{ }^{\circ} \mathrm{C}$ (Table II). According to the superheat multipliers in Table IV, a superheat of $150{ }^{\circ} \mathrm{C}$ gives a FD that is 18 pct longer than for $60{ }^{\circ} \mathrm{C}$. Hence, compared to AISI 1025 steel poured with a $60{ }^{\circ} \mathrm{C}$ superheat, the FDs for the CW$12 \mathrm{MW}$ high-nickel alloy poured with a $150{ }^{\circ} \mathrm{C}$ superheat are smaller by a factor of only $C_{\text {alloy }} \times C_{\text {Niyama }} \times C_{\text {superheat }}=$ $0.979 \times 0.66 \times 1.18=0.76$, as opposed to $C_{\text {alloy }} \times C_{\text {Niyama }}=$ $0.979 \times 0.66=0.65$, if the two alloys were poured with the same superheat.

\section{CONCLUSIONS}

A total of 55 plates of varying lengths were cast at five foundries, in an effort to develop FD rules for the nickelbased alloys CZ-100, M-35-1, and CW-12MW, as well as for the austenitic stainless steel CN-7M. In order to develop the property databases necessary to simulate casting of these alloys, temperature data were recorded for each alloy during the casting trials. These measured data were used in conjunction with material property simulation (JMatPro) to develop the necessary solidification path and property data for each alloy. Reasonable agreement is obtained between the measured temperatures and the temperatures predicted by casting simulation using the newly developed property data. Some shortcomings in the solidification path calculations by JMatPro are noted.

A comparison of the radiographs taken of the plates with the corresponding MAGMASOFT casting simulation results reveals generally good agreement. The centerline shrinkage indications on the X-rays for those plates for which the FD was exceeded are found to correlate well with the Niyama criterion. A quantitative relation is established between the measured ASTM X-ray levels and the predicted minimum Niyama criterion value for all but the CZ-100 alloy, which appears not to suffer from shrinkage defects. The CN-7M, CW-12MW, and M-30C/M-35-1 alloy castings are found to be radiographically sound if the minimum Niyama value exceeds unity.

The results of a large number of additional simulations are used to develop general FD rules for the $\mathrm{CN}-7 \mathrm{M}, \mathrm{CW}$ $12 \mathrm{MW}$, and M-30C/M-35-1 alloys. The rules build directly on previously established C\&LA and high-alloy steel rules ${ }^{[2-5]}$ and account for differences in the alloy composition, casting conditions, and desired soundness level through the use of multipliers. It is shown that the new rules accurately predict FDs for the casting trials performed within the course of the present study. The FDs for the high-nickel alloys studied here are found to be at least 25 pct shorter than those for a typical low-alloy steel.

\section{ACKNOWLEDGMENTS}

This work was prepared with the support of the United States Department of Energy (DOE) Award No. DE-FC3602ID14225. However, any opinions, findings, conclusions, or recommendations expressed herein are those of the authors, and do not necessarily reflect the views of the DOE. We are 
indebted to Malcolm Blair and Raymond Monroe, SFSA, for their work in helping organize the trials and recruiting foundries to participate. Most important, we thank the participants in the plate-casting trials (A.G. Anderson, Ancast, Southern Alloy, Stainless Foundry \& Engineering, and Wollaston Alloy) for their substantial investments of both time and resources. This work could not have been accomplished without their shared efforts. In particular, we are very grateful to Vasile Ionescu, A.G. Anderson, for his help in organizing, preparing for, and performing the TC casting trials.

\section{REFERENCES}

1. Risering Steel Castings, Steel Founders' Society of America, Crystal Lake, IL, 1973.

2. K.D. Carlson, S. Ou, R.A. Hardin, and C. Beckermann: Metall. Mater. Trans. B, 2002, vol. 33B, pp. 731-40.
3. S. Ou, K.D. Carlson, R.A. Hardin, and C. Beckermann: Metall. Mater. Trans. B, 2002, vol. 33B, pp. 741-55.

4. Feeding \& Risering Guidelines for Steel Castings, Steel Founders' Society of America, Crystal Lake, IL, 2001.

5. S. Ou, K.D. Carlson, and C. Beckermann: Metall. Mater. Trans. B, 2005, vol. 36B, pp. 97-116.

6. JMatPro, Sente Software Ltd., Surrey Technology Centre, Surrey, GU2 7YG United Kingdom.

7. Personal Daq, IOTech, Inc., Cleveland, OH 44146.

8. ASTM E94-00, Annual Book of ASTM Standards, vol. 03.03, Nondestructive Testing, ASTM, Philadelphia, PA, 2002.

9. ASTM E446-98, Annual Book of ASTM Standards, vol. 03.03, Nondestructive Testing, ASTM, Philadelphia, PA, 2002.

10. K. Carlson, S. Ou, R. Hardin, and C. Beckermann: Int. J. Cast Met. Res., 2001, vol. 14, pp. 169-83.

11. MAGMASOFT, MAGMA GmbH, 52072 Aachen, Germany.

12. C.E. Bates and L.C. Tillery: Atlas of Cast Corrosion-Resistant Alloy Microstructures, Steel Founders' Society of America, Des Plaines, IL, 1985.

13. E. Niyama, T. Uchida, M. Morikawa, and S. Saito: Am. Foundrymen's Soc. Int. Cast Met. J., 1982, vol. 7 (3), pp. 52-63. 